Accepted for publication in Energy Policy (February 2009).

\title{
Environmental climate instruments in Romania: A comparative approach using dynamic CGE modelling
}

\author{
Rodica Loisel \\ CIRED-CNRS $^{1}$
}

\begin{abstract}
This study simulates a CO2 permit market in Romania using a dynamic general equilibrium model. The carbon constraint is set at $20.7 \%$ below the reference emissions level for sectors eligible according to the EU-ETS (European Union Emission Trading Scheme). Free permit distribution enhances growth despite a severe emissions cap, because environmental regulation stimulates structural changes (Porter, 1991). That is, grandfathering allows sectors additional resources to invest in developing technologies, but it also raises the $\mathrm{CO} 2$ abatement costs because of energy rebound effects from enhanced growth. Results under endogenous growth (Romer, 1990) are very similar to those obtained under an exogenous growth scenario (Ramsey, 1928), as the substitution effects are responsible for the majority of variations; in addition, Romanian research activities are too modest to significantly impact this system. The abatement cost per unit of GDP is higher under endogenous growth, as spillover effects reduce incentives to invest. Technological diffusion continues to have a positive impact on economic growth, which counterbalances the free-riding attitude adopted by some energyintensive sectors, such as glass and cement.
\end{abstract}

Keywords: tradable permits, Romania, endogenous/exogenous growth, spillover effects.

JEL Classification: C68, H2, Q43, Q5.

\section{Introduction}

The international environmental context has deeply changed with the ratification of the Kyoto Protocol and the implementation of the European Union's Emission Trading Scheme (EUETS) in 2005. These agreements have greatly influenced national climate policy in Romania, especially since the country acceded to the European Union in 2007. Some national actions include the ratification of the Kyoto Protocol ${ }^{2}$ and the transposition into Romanian legislation of the European Directive that sets the terms of carbon trade (Directive 2003/87EC; EC, 2003).

As in most Eastern European countries, energy consumption in Romania has undergone a significant drop during the transition from a centrally planned economy to a market economy. This decrease is partly due to a decline in economic activity, particularly after the dissolution

\footnotetext{
${ }^{1} 45$ bis, av. de la Belle Gabrielle, 94736 Nogent sur Marne, France. Email: rodica@centre-cired.fr.

2 Romania ratified the UNFCCC (1994) and the Kyoto Protocol (2001) with the commitment to reduce greenhouse gas emissions by 8\% compared to 1989 levels over the period 2008-2012.
} 
of CMEA (Council of Mutual Economic Assistance) in 1991, as well as to structural transformations that took place during the transition. Consequently, Romanian GHG emission levels decreased by $50 \%$ in 2002 relative to their 1989 levels. Besides industrial and economic transitions, energy supply transformations are also noteworthy, as the commissioning of the first nuclear power reactor in 1996 allowed the country to further reduce GHG emissions. Before the end of the first commitment period of the Kyoto Protocol (2012), it is likely that GHG emissions will be below the benchmark set for Romania, even given scenarios with high economic growth rates (RME, 2005; RME, 2006c). Yet after this period, rapid growth could lead to emissions levels 40\% higher than the 2002 levels (RME, 2006b).

Romania has a diverse range of natural resources, such as oil, gas, coal, uranium and other significant renewable energy resources ${ }^{3}$ including hydraulic energy, that ensures up to $67.7 \%$ of the country's energy independency (2003). The lifetime of these resources is estimated at 240 years for coal, 121 years for lignite and 122 years for uranium, while it is only 14 years for both oil and gas ${ }^{4}$ (RME, 2006a). In this context, coal and uranium are the main energy resources for the country's energy balance; as such, two new nuclear plants are scheduled for 2010 and 2015 (RME, 2006b). As coal remains the main energy resource in the long run, the study of the evolution of emissions is essential to ensure long-term, sustainable economic development. Thus, the main objective of this research project is to estimate the costs of carbon reduction using two growth scenarios of the Romanian economy. Environmental policies are tested within these two scenarios by focusing on quantities and prices. One consists in the implementation of a $\mathrm{CO} 2$ permit market; the other consists in the introduction of a tax on $\mathrm{CO} 2$ emissions.

Note that technological progress can reduce the costs of abatement (Goulder and Schneider, 1999). Most models confirm that the cost reduction is sensitive to the level of technological change, concluding that pollution reduction is accelerated through the spillover effects that technological progress generates. In contrast, other models assign a major role to the abatement functions of interfactorial substitution effects (Nordhaus, 2002).

The recent literature on this topic presents technological progress as the main factor affecting the evolution of and reduction in greenhouse gas emissions because of the scarcity of energy options with low carbon emissions (Tietenberg et al., 1999). Analyses of the tradable permit market have shown that innovation can reduce abatement costs, because environmental research tends to reduce emissions, increase the supply of permits and lower the equilibrium price (Buonanno et al., 2003; Manne and Richels, 2002). Environmental regulation can thus improve research policy, as it creates incentives for the development of new technologies (Porter, 1991). However, some have shown that environmental constraints do not necessarily improve environmental research, because the pace of innovation slows down as energy prices rise and research spending diminishes (Kohler et al., 2006; Popp, 2002).

The impact of technological progress on the economy depends on the level of technological diffusion. Spillover effects are considered to be a growth factor, even if they generally reduce incentives to innovate. From a climate policy perspective, the diffusion of innovations leads to a higher permit price, because diffusion creates and stimulates so-called "free-riding"

\footnotetext{
${ }^{3}$ Primary energy resource shares in 2003 are: $34.8 \%$ gas, $25.7 \%$ oil, $23.4 \%$ coal and $5.1 \%$ for hydroelectric and nuclear-electric energy. National production is around 5.2 million tonnes per year for oil and 12.9 billion $\mathrm{m}^{3}$ for gas.

${ }^{4}$ The country's reserves are estimated at 73.7 million tonnes for oil and to 184.9 billion $\mathrm{m}^{3}$ for gas (RME, 2006a)
} 
behaviour. This leads to a lower supply of tradable permits, thus increasing the equilibrium price. The macro-level impact is the opposite; spillover effects lower total abatement costs due to the positive effects they induce on growth (Buonanno et al., 2003).

Theoretical models show that spillover effects positively affect growth, but in practice, growth is dependent on past innovations as well as on capital stock. This latter concept defines progress as an inertial evolution that is difficult to change (Ha-Duong et al., 2004). That is, even if cheaper and more effective technologies are available, old technologies linger on because of their sunk costs. This blocked entry of new technologies is conventionally called a "lock-in effect" (Weyant and Olavson, 1999). Yet, despite this inertial aspect to growth, abatement measures can encourage the substitution of fossil-based technologies with cleaner technologies as well as can help reduce the price of technological progress by highlighting that learning and innovation are cost-saving activities.

Thus, debates aimed at developing an optimal abatement trajectory involve two opposing perspectives on action, namely, immediate action ("act now") versus initiatives undertaken in the future ("wait and see"). Abatement costs appear lower in the future due to increased technical progress, which seem to justify fewer abatement efforts in the short-term (Manne and Richels, 2002; Wigley et al., 1996). However, efforts to reduce emissions are increasingly beneficial the longer they have been enacted (Goulder, 2004), while the adoption of environmental measures can encourage the adoption of cleaner technologies. This increases the speed of technology diffusion and accelerates abatement in the long-term (Goulder and Schneider, 1999).

This research further explores the effect of technological change on climate policies and abatement cost in Romania using a general equilibrium framework. Through intertemporal dynamics, the model exogenously simulates active population growth (Ramsey, 1928) and endogenously introduces the technological progress originating in fundamental research (Romer, 1990). To explicitly describe the permit market, the model adopts appropriate disaggregation criteria and builds a multi-sector structure, as discussed in section 2. Two distribution rules are tested, including allowances that are freely distributed among sectors, as mostly provided within the European Trading Scheme (ETS) until 2012, as well as allowances that are auctioned to participants, as per the European Commission's goal to gradually increase auctioning until 2020 (EC, 2008). Tax and permit analysis drive the two modelling growth motors so that auctions act as a carbon tax when permits are sold at the same price, as described in section 3. Final remarks on the findings as well as policy recommendations are presented in the final section.

\section{Theoretical specifications of the model and data}

The neoclassical growth model is often attributed to Ramsey (1928), Cass (1965) and Koopmans (1965); in fact, it is a reduced form of a saving-investment model with a single infinitely-lived representative agent. Another analytical understanding of growth was developed by Solow (1956) with a focus on the productivity of production factors. In both the Ramsey and Solow models, the long-run growth rate depends on exogenous technological progress and population growth rates. The neoclassical model was developed further by Romer (1986) and Lucas (1988), Aghion and Howitt (1992), Grossman and Helpman (1991), and Barro and Sala-i-Martin (1992). These new growth theory models explained growth endogenously using three mechanisms: capital accumulation externalities, human capital accumulation and the existence of a stock of knowledge. This literature assumes that 
technological progress is a production process and that there is a common stock of knowledge possessed by society. Human capital acts on economic growth first by participating in production process and second by increasing productivity through the research, innovation and diffusion of new technologies. Knowledge stock, moreover, is a public good that generates spillover effects derived from capital accumulation; it compensates for decreases in the marginal productivity of capital and allows the economy to grow at positive rates in the long-run.

Applications of this new growth theory to environmental issues began in the 1990s with Nordhaus (1999), Goulder and Schneider (1999), Goulder and Mathai (2000), Buonanno et al. (2003). These studies endogenously analyse firm reactions to an increase in energy prices that resulted in improving energy efficiency through research and development investment (R\&D). These applications to energy and the environment are based on a relationship among R\&D supply, human capital, growth rates and environmental regulations; they focus on the effects of public policies on technical changes that depend on the market structure, investments and the actions and anticipations of individuals. For instance, the implementation of a carbon tax increases energy prices and stimulates the demand for innovation; innovations in cleaner technology are then encouraged, depending on the profitability of the corresponding patents. Among these models, top-down approaches are the most explicitly cited as well as the least abstract methods for modelling technological progress (Weyant and Olavson, 1999). General equilibrium models in particular can more precisely take into account socio-economic contexts as well as growth feedback, both of which are important, because technological change usually influences economic and social progress.

Our modelling framework retains the three growth assumptions discussed in Goulder and Schneider (1999), namely, the accumulation of physical capital (standard), the development of intangible capital (knowledge stock) and the exogenous growth of the active population. Our dynamic structure has an infinitely-lived representative household, as in the Ramsey model (1928), and introduces population growth into the R\&D model of Romer (1990). The main difference between our model and most other models involves the nature of knowledge stock. Here, we relate knowledge stock to fundamental research activities that develop and integrate technological innovations. That is, environmental policies have general effects on growth but do not explicitly influence depolluting efforts through specific technologies. Two main factors inform this assumption: the lack of sector data on environmental R\&D investment in Romania and the absorption capacity of new technologies in all branches due to restructuring processes.

Our model describes the innovation mechanisms through which the production of knowledge and its diffusion influences the development of capital and causes inter-sectoral spillover effects. Romer's model is adapted here to a multi-sector economy structure as well as to a different type of factor disaggregation; still, the growth mechanism is similarly based on human capital and knowledge accumulation and diffusion. That is, in our model, individuals have an infinite time horizon with perfect forward-looking anticipations, but contrary to the Ramsey model, labour is endogenously supplied over time, and the economy is open to the trade with the rest of the world. Since Romania is a small economy, world-market goods prices are exogenous, and the substitutability between domestic and imported goods is imperfect (Armington, 1969). Production factors are fully mobile across sectors. All prices in the model are in relative terms, and the wage rate is the numeraire in the model. Production is disaggregated into 14 sectors: electricity, coal, oil, gas, metallurgy, glass, cement, paper, chemistry, transports, agriculture, construction, services and other activities. To model 
innovation, we introduce two additional sectors, research and development. The research sector produces inventions, such as patents or technological knowledge, which are sold to the development sector in order to produce new technologies for a final goods sector. Equations are presented in Appendix 2.

The representative consumer receives a fixed share of dividends from the final goods sectors, including wages paid by the final goods producer, monopoly profits from the development sector, as well as transfers from the state and firms. Households maximise the net of environmental gains utility by making a trade-off between leisure and consumption under the assumption of a constant fixed elasticity of substitution (CES). The consumption basket is aggregated following CES function properties. Welfare is calculated using the Hicksian measure of equivalent income variation.

The final goods sector is described using a constant returns-to-scale production function following the KLEM approach, as it is the most commonly adopted approach in the energy literature (Nordhaus, 1992; Burniaux et al., 1992; Lee et al., 1994; Beaumais, 1995; McKibbin and Wilcoxen, 1995). Its nested structure follows the same principle in all final goods sectors (see Appendix 1). At the highest nest, production ( $Y j)$ is a fixed composition of intermediate materials $M j$ and aggregate materials $K L E j$. The capital-energy composite (KEj) can be traded off with labour, yet to a lesser extent in capitalistic sectors. A new element is added to standard physical capital to each sector $j$, namely, development capital that represents the fraction $\theta_{j}$ of the aggregate materials out of all innovative capital varieties $(A)$ produced by the development sector (Ydev):

$K E_{j}=A_{2 j}\left[\alpha e_{j} E_{j}^{1-\frac{1}{\varepsilon_{K E}}}+\alpha k_{j} K_{j}^{1-\frac{1}{\varepsilon_{K E}}}+\left(1-\alpha e_{j}-\alpha k_{j}\right)\left(\theta_{j} \cdot A \cdot Y d e v\right)^{1-\frac{1}{\varepsilon_{K E}}}\right]^{1 /\left(1-\frac{1}{\varepsilon_{K E}}\right)}$

The variable $A$ indicates the effects of knowledge stock from the research sector on the final goods technology that ensures the diffusion of spillover effects.

The carbon market functions as a zero-sum game, meaning that the more $\mathrm{CO} 2$ a sector emits, the greater are the efforts required from other sectors to decrease their emissions.

$\sum_{j} \sum_{i}\left(C O 2_{i, j}-\overline{C O 2_{i, j}}\right)=0$,

where $\overline{C O 2_{i, j}}$ is the number of free allowances and $C O 2_{i, j}$ is the emissions of sector $j$ that employs a production technology using energy input $i$.

We assume that the producer modifies energy prices according to value of permits subject to the constraint that at equilibrium, the firm's profit is null. This means that the scarcity rent (i.e., the value of granted permits) is also integrated into the price frontier at the lowest level of the production structure. This technique appears efficient from an economic point of view, because price signal is transmitted downstream into production technology, encouraging substitutions between energy inputs and capital or labour (Burniaux et al., 1992). Another option is to consider the permit or tax as an input to the production function, as in McKibbin and Wilcoxen (1995) and Nordhaus (1992).

The optimisation function is as follows:

$\operatorname{Min} P_{E j} E_{j}=\sum_{i}\left[\operatorname{cin}_{i, j} P c i_{i, j}+\operatorname{Pper}\left(C O 2_{i, j}-\overline{C O 2_{i, j}}\right]\right.$ s.c. $/ E_{j}=A_{3 j}\left[\sum_{i}\left(\alpha_{E i, j} \operatorname{cin}_{i, j}{ }^{1-\frac{1}{\varepsilon_{E j}}}\right)\right]^{\frac{1}{1-1 / \varepsilon_{E j}}}$, 
where $P E$ is energy price, $E$ is energy input, $\operatorname{cin}_{i}$ is the intermediate consumption of resource $i$ (including coal, gas, electricity, or oil), Pper is the permit price, which is the same for all sectors, and $\mathrm{PCi}$ is the price of input $i$. The product $\operatorname{Pper} \sum_{i} \overline{\mathrm{CO} 2_{i, j}}$ is defined as the scarcity rent, and the expression Pper $\sum_{i}\left(\mathrm{CO}_{i, j}-\overline{\mathrm{CO} 2_{i, j}}\right)$ represents the sector permit balance, which might be either positive or negative, meaning that a sector is a buyer or seller on the permit market, respectively. The optimal demand function regarding energy consumption follows the CES formula; it is modified here with an increase in production possibilities due to free allowances and a reduction with the permit value weighted with the input coefficients of emissions (coef):

$\operatorname{cin}_{i, j}=\left(\frac{E_{j}}{A_{4 j}}\right)^{1-\varepsilon_{E j}}\left[\frac{\alpha_{E i, j}\left(P_{E j} E_{j}+\operatorname{Pper} \sum_{i} \overline{\operatorname{CO} 2_{i, j}}\right)}{P c i_{i, j}+\operatorname{Pper} \cdot \operatorname{coef} f_{i, j}}\right]^{\varepsilon_{E j}}$.

The formalisation of the tradable permit market is based here on the implicit cost of abatement; other models consider the explicit form of cost reduction based on the assumption that agents have different options in abating pollution (Ellerman and Decaux, 1998). This assumption is applied on a global scale in order to compute the specific cost of abatement for each region, country or sector. Each abatement potential is used to establish the quantity of quotas allowed to participants in the permit trade. The implicit, unique cost employed in our model is justified by the fact that the potential for abatement is ex ante established, as it is proportional to historical emissions and equivalent to the abatement objective of $20.7 \%$ from the reference emissions.

The introduction of carbon taxes is similar to the permit market described above, except that initial allocation is zero. The analogy with permit auctioning is perfect if all permits are auctioned at the same price. The relationship between the abatement costs and the tax level follows the principle underlying the quantity-based approach.

At the lowest nest of the production technology, the energy inputs are a CES-Armington aggregation of domestic and imported inputs. The source of carbon dioxide emissions is the primary inputs from all energy sectors ${ }^{5}$. It is assumed that emissions are proportional to the amount of primary energy used in each sector. The environmental policy is also applied to imported fossil fuels, since their combustion takes place domestically. It is assumed that both domestic and imported energy inputs have the same emission coefficients in order to avoid substituting domestic inputs for imported inputs due to environmental regulation evasions.

The sector investment is the result of a firm's trade-off between the development of capital goods, on the one hand, and conventional capital accumulation, on the other hand. Most capital represents the last form of investment, which at each period meets the demand for depreciated capital. This form of capital affects productivity only through a substitution effect, while development goods improve productivity through spillover effects.

Dynamic specifications are adopted according to active population evolution (exogenous growth) and technological knowledge accumulation (endogenous growth). From an empirical point of view, active population dynamics are limited by the demographical decline recorded

\footnotetext{
${ }^{5}$ The electricity sector includes parts of the gas distribution network, and thus, some $\mathrm{CO} 2$ emissions are associated with this sector and its output.
} 
in Romania after 1990. However, the active population is assumed to be increasing, as the current unemployment rate is officially set around $8 \%$ but is unofficially at $40 \%$ (Stanculescu and Berevoescu, 2004). The active population growth rate is thus calculated to be positive with an annual rate set at $0.1 \%$.

A representative household maximises its intertemporal utility subject to intertemporal budgets constraint defined by the following per capita variables:

$$
\begin{aligned}
& \underset{C_{t}, l_{t}}{\operatorname{ax}} U=\frac{1}{1-\theta} \sum_{t} \frac{1}{(1+\rho)^{t}} u\left(C_{t}, l_{t}\right)^{1-\theta} \\
& s / c \sum_{t} \frac{(1+n)^{t-1}\left(p k_{t} K H_{t}+w_{t} l_{t}+T R S r_{t}\right)}{\prod_{s=1, t}\left(1+r_{s}\right)}=\sum_{t} \frac{(1+n)^{t-1}\left(p c_{t} C_{t}+S a v H_{t}+T R S p_{t}\right)}{\prod_{s=1, t}\left(1+r_{s}\right)},
\end{aligned}
$$

where $\theta$ is the intertemporal elasticity of substitution, $\rho$ is the time preference rate, $r$ is the discounting rate, TRSr and TRSp are household received and paid transfers, respectively, Sav is individual savings, $p k$ is capital price, $K H$ is received dividends, and $w \cdot l$ is the net total wage.

Consumption is the aggregate of goods from the final goods sector that are combined into a CES function that takes into account intratemporal budget constraints at each period $t$. The dynamics of aggregate consumption $C$ are determined by the Euler equation as follows:

$$
C_{t}=C_{t+1}(1+n)\left(1+g_{T}\right)\left(\frac{1+\rho}{1+r_{t+1}}\right)^{\frac{\sigma}{\sigma \theta+1}}\left(\frac{p c_{t+1}}{p c_{1}}\right)^{\frac{\sigma}{\sigma \theta+1}}\left[\frac{1-\beta+\beta\left(\frac{\beta}{1-\beta} \frac{p c_{t+1}}{w_{t+1}}\right)^{\sigma-1}}{1-\beta+\beta\left(\frac{\beta}{1-\beta} \frac{p c_{t}}{w_{t}}\right)^{\sigma-1}}\right]^{\frac{\sigma \theta}{\left(1-\frac{1}{\sigma}\right)(\sigma \theta+1)}},
$$

where $g_{T}$ denotes the growth rate at the final period $T$ that deflates consumption value at each period; other notations include $\beta$ for the share of leisure in consumer utility and $\sigma$ for the substitution elasticity between leisure and consumption. This equation shows the trade-off between present and future consumption as a direct function of three factors: the ratio between the time preference rate and the future discounting rate, the ratio between the aggregate price of consumption in present and future, and the ratio between the priceweighted index of consumption and the leisure price.

At the firm level, capital accumulation is based on backward-looking specifications, function of the rate of capital depreciation and the initial capital stock:

$K_{t+1}=\left[I_{t}+(1-\delta) K_{t}\right] /\left[(1+n)\left(1+g_{T}\right)\right]$.

The endogenous growth framework based on Romer (1990) supposes an increase in the productivity of all inputs. The development mechanism includes three assumptions: 1) technological change induces growth, 2) the market values resulting innovations, and 3) knowledge acts as a non-rival input into the research sector. These assumptions are the heart of endogenous growth theory: non-rival knowledge implies a free diffusion of externalities in which effects spread directly into the research sector and indirectly into the final goods sector.

The research sector employs capital and labour factors in a constant returns-to-scale CobbDouglas specification in order to produce $\dot{A}$ patents, that is, $\dot{A}=\gamma L r^{\alpha} K r^{1-\alpha} A$. Knowledge stock $(A)$ is freely employed at each period, as it is non-rival and non-exclusive in this sector, but it becomes perfectly exclusive when it is valued on the market. The research sector benefits from externalities generated by knowledge stock that are partly internalised through 
public subsidies; patent marginal cost equals $\left(1+\tau^{s r}\right) p r$, where $p r$ is the selling price of the patent to the development sector.

The development sector is represented by different firms; each of them purchases one patent and produces one variety of development goods. The number of these firms increases with the number of patents resulting from the research sector. Romer's model explicitly uses a monopoly structure to describe this sector's activities, because profit becomes the only motivation to produce capital goods even though one cannot perfectly value the externalities generated by the output of these firms.

Each firm's production technology requires a specific patent, labour, capital as well as 14 other inputs issued from the productive sector, much like final goods producers. As in the reference model, for simplicity we assume that there are $A$ firms, each of which produces the same product quantity (Ydev) at the same marginal cost (Pbiv). Total production is an additive function, Yiv $=\sum_{i=1}^{A} Y d e v=A \cdot Y d e v$.

The total profit maximisation function takes account of symmetric production conditions:

$\underset{\text { Yiv }}{\operatorname{Max}} \pi_{\text {tot }}=\underset{\text { Yiv }}{\operatorname{Max}}\left(P_{\text {mon }}(\right.$ Yiv $\left.)-P_{\text {biv }}\right)$ Yiv.

The usual monopoly specifications are introduced. The market price Pmon equals the marginal production cost adjusted according to the elasticity of development goods demand in the final goods sector: $P_{\text {mon }}=P_{i v} /\left(1-1 / \sigma_{K E}\right)$.

Intertemporal profits discounted with the interest rate equal total patent costs, as follows:

$\sum_{t} \pi_{t} / \prod_{s=1}^{t}\left(1+r_{s}\right)=p r_{t}$

Market power in the monopolistic development sector forces the private optimum to diverge from the social optimum. This dynamic is corrected through state subsidies granted for the purchase of development goods that maintains the monopolistic incentives to produce. Selling price then equals production cost: $P_{b i v}=\left(1-\tau^{s d}\right) P_{m o n}$.

The growth mechanism allows the economic system to evolve at the rate of knowledge accumulation, $g t: g_{t}=\frac{A_{t}-A_{t-1}}{A_{t-1}}=\gamma L r_{t}^{\alpha} K r_{t}^{1-\alpha}$.

The resolution of a dynamic module implies the deflation of variables with the growth rates, that are $n$ for the active population and $g_{T}$ for the long-run innovation growth rate. This technique allows us to compute per capita values of variables and to compare them with the reference values. The modified golden rule thus takes the form $\left(1+g_{T}\right)(1+n)=\left(\frac{1+r_{T}}{1+\rho}\right)^{\frac{\sigma}{\sigma \theta+1}}$, where $r_{T}$ is the interest rate at the last period, $\theta$ is the intertemporal elasticity of substitution, $\rho$ is the time preference rate, and $\sigma$ is the elasticity of substitution between leisure and consumption.

Equilibrium conditions are set at four levels. Goods and services markets are cleared in volume by equalising supply with demand as well as in value through factor price frontier. Labour and capital markets are cleared in value as shown in annex 2. In the current scenario, external debt is set to zero at each period. The equilibrium between savings and investments is set by adjusting the interest rate; the solvability of the model is assured by replacing this 
condition with the Walras law that checks the general equilibrium at each period through a control variable, denoted as walras:

walras $_{t}=\operatorname{pinv}_{t} \operatorname{InvS}_{t}+\operatorname{piv}_{t} \operatorname{Yiv}_{t}+\operatorname{prd}_{t} A_{t-1} /\left(1+g_{T}\right)-\left(\operatorname{SavS}_{t}+\operatorname{SavH}_{t}+\operatorname{SavE}_{t}\right)$.

Terminal conditions, which are necessary for approximating the infinite time horizon with a finite numerical model, are taken into account here by using the modified golden rule for consumer accounts as well as the usual identity $\operatorname{In} v_{T}=(n+\delta) K_{T}$ for investment accounts. Alternative terminal constraints have been developed by Lau et al. (2002) and Böringher et al. (2007) based on a mixed complementarity problems (MCP) that endogenises the growth rate at the last period. The investment growth rate at the last period equals the growth rate of capital, production or any other stable quantity variable, or $I_{T} / I_{T-1}=Y_{T} / Y_{T-1}$. Using this terminal condition shows similar results for fewer periods as compared to the usual non linear programming solver (NLP); for example, 17 periods under NLP represent 10 periods under the MCP approach. Applying these two terminal conditions to our model indicates that the number of periods is high enough to ensure the convergence and it indicates no sensitivity to the terminal condition. Our simulations were conducted using GAMS/MCP software (Brooke et al., 1998) and the PATH solver.

\subsection{Calibration procedure}

The social accounting matrix (SAM) is built based on data provided by the Romanian National Accounts for the year 2003 (NIS, 2006a). Production prices in all final goods sectors are normalised to unity, and the intermediate consumption prices are computed in line with the factor price frontiers following a bottom-up approach. The calibration of volumes and flows between the producer, the state, households, saving-investment accounts and the rest of the world are based on values issued from the SAM.

The elasticities of substitution are derived from energy studies that have been applied to industrialised countries (Bohringer and Rutherford, 1997; Kemfert and Welsch, 2000; Piazolo, 2000). Some rates are modified according to particular empirical frameworks; these frameworks take into account rapid economic transformations during transition, enterprise restructuring, and technology modernisation that involve deep transformations in the structure of various economic and other factors. In terms of intermediate energy consumption, producers tend to favour electricity in the long-run together with the replacement of imported gas technologies by hydro and nuclear capacities (RME, 2005, 2006a). Energy efficiency gains are expected in all sectors; investment needs for technology modernisation justify capital substitution for a fixed parameter of 1.3 in the oil sector and 2.6 in the energy intensive sectors. Labour substitution is significant in light industries and services ( $\sigma=2)$, but it is less important in the agriculture, as this sector already employs $35 \%$ of the active population and thus has a limited absorption capacity. The trade-off between imported and domestic products is in favour of imports for gas and oil $(\sigma=0.7)$ and in favour of domestic goods in agriculture (2.5) and construction (2.7). Intratemporal trade-offs between leisure and consumption are in favour of the latter when the substitution value is set at 1.9. With data for prices, volumes and substitution elasticities, the calibration of parameters follows the usual procedure employed for CES and Leontief functions.

Endogenising R\&D-based growth increases the difficulties in calibrating the key parameters (Gillingham et al., 2008; Otto et al., 2008). Our parameterisation is inspired from the Mage's (2004) application of Romer's model to international trade. 
Knowledge production at the current period is calibrated using the relation $A_{2003}=g_{2003} \sum_{t}^{2002} A_{t}$, which indicates that the innovations at the reference period are the product between the growth rate and the stock of knowledge accumulated until 2003. Knowledge stock includes past R\&D expenses starting with 1995 and equals $\left(\sum_{t=1995}^{2002} A_{t}\right)$.

Table 1. Research expenses in Romania

\begin{tabular}{|l|l|l|l|l|l|l|l|l|l|}
\hline Year & 1995 & 1996 & 1997 & 1998 & 1999 & 2000 & 2001 & 2002 & 2003 \\
\hline Current price s in $10^{12}$ lei & 0.577 & 0.768 & 1.465 & 1.833 & 2.196 & 2.962 & 4.593 & 5.743 & 7.621 \\
\hline
\end{tabular}

Source: NIS, $2006 b$.

The consideration of patents as a market product is appropriate for the Romanian context only in the late 1990s after the adoption and application of competition laws on property rights (RMT, 2006). Before these laws, research output was a public good. Restrained time-interval knowledge stock is compensated by the fact that the depreciation of innovations is not taken into account; in practice, this depreciation rate is relatively high at about $12 \%$ (Nadiri and Prucha, 1996). We implicitly assume that stock of knowledge capital by sector changes very slowly: once capital is installed, the time lag necessary to switch equipment is rather long, given inertia in technological changes. Since the growth rate in 2003 is about 5\%, knowledge stock is estimated to one, while the price of innovation is calibrated at around 3.8, net of subsidies. For comparison, the standard capital price is close to unity. In Nordhaus (1992), the cost of research is multiplied by four in comparison with conventional investment prices, reflecting market imperfection. Subsidies are assessed against public funds in the research sector, which in 2003 obtained about 50\% of its production costs from the state (NIS, 2006b).

Production technology in the development sector resembles the input-output structure of hightechnology sectors (NIS, 2006a). Its production cost calibration is in line with the production principles in the final goods sector, and the sector's monopoly price is obtained by summing the monopoly rent. The last calculation equalises state aide and rate amounts to 0.64 of the marginal production cost.

Investments in research are reported as investments in physical capital, so to equilibrate the SAM, investment accounts are debited with respective research expenses. As for investments in development goods, these are included in the intermediate consumption of high-technology goods, thereby the new equilibrium debits the intermediate consumption matrix.

\section{Simulations and discussion}

The simulated environmental policy sets a constraining goal of $20.7 \%$ of emissions of the base-year level, which corresponds to the target set by the Romanian National Allocation Plan according to the EU-ETS (RME, 2006c; EC, 2007). This constraint is applied to eligible sectors, namely, electricity, refineries, metallurgy, glass, cement and pulp and paper production. Simulations are conducted for 40 periods, with shock gradually applied between 2008 and 2012. The application of taxes is analogous to permit auctioning, since all permits are auctioned at the same price. We first analyse the implementation of environmental regulation under endogenous growth as compared with the reference year 2003 (3.1.) and then compare these results with those obtained using an exogenous growth approach (3.2.). Selected results are presented in Appendix 3. 


\subsection{Prices versus quantities in an endogenous growth approach}

In order to generate comparable results, the same environmental benefit is set for both tax and free permit scenarios. This represents an abatement of $19.8 \mathrm{Mt} \mathrm{CO} 2$ from eligible sectors, resulting in a marginal abatement cost of 3.8 euros for the tax scenario and 5.8 euros for the permit scenario. The difference in equilibrium price between the grandfathering and the permit auction cases is explained by the different volumes of traded permits between the two scenarios, which are 2.28 $\mathrm{M}$ and $56.3 \mathrm{M}$ permits, respectively.

Economic growth follows different trajectories. It drops in the tax scenario $(-0.33 \%)$ but increases in the free permit scenario $(0.15 \%)$. Two main features can explain the positive effect on economic growth in the free permit scenario, namely, market flexibility and the grandfathering scheme used to allocate initial permits. Market flexibility is due to the differences in abatement costs across sectors. Permit trading exploits this difference, thereby reducing $\mathrm{CO} 2$ emissions in those sectors with the fewest cost abatement opportunities. Thus, the allowance of free permits increases flexibility as compared with the tax scenario (Baker et al., 2008). Similarly to Wing's (2003) study, we find that the introduction of a carbon tax reduces $R \& D$ investments; this slows technological change and output growth.

Figure 1 . The evolution of the growth rate $(\%$, reference $=5 \%)$

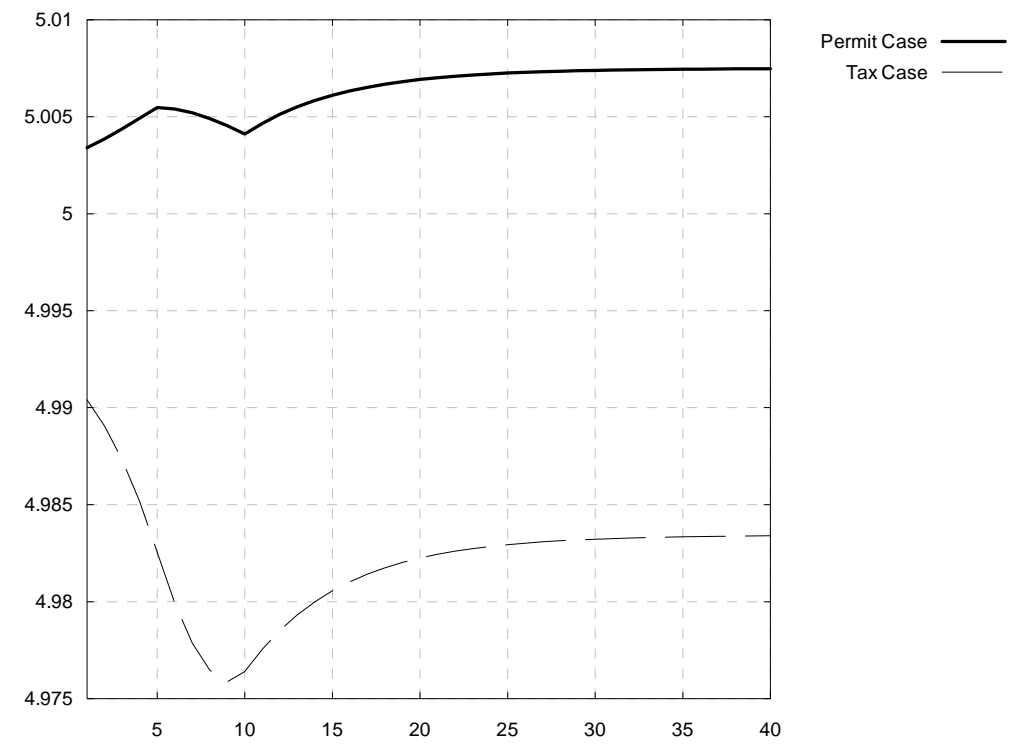

The policy applied at the sixth period has an announced character and thereby agents are able to anticipate the future system of prices and adapt their behaviour accordingly. Research and development activities are affected during the shock (2008-2012); since this shock is applied early, agents have only a few periods to adjust their behaviours.

In the permit scenario, households anticipate an increase in aggregate consumer price during the shock as well as a post-2012 decrease in this price; thus, consumption follows an inverse evolution. It decreases with the anticipation of a price increase, and it rises after the shock due to a decrease in prices (Fig. 2). Decreased consumption at the beginning of this interval causes savings to increase and enhances positive growth. Increased savings during this period is also the result of an anticipated increase in interest rate, meaning that investments are encouraged when interest rates are lower. Additionally, anticipating an increased patent price for innovations implies more profits for the research sector, which encourages production and positively effects growth. The growth rate is continuously positive even if consumption volume decreases during the first 10 years due to the positive effect of agents on the health of 
the future pricing system. In the end, after both the shock and the subsequent recovery from the shock, research output decreases and the volume of development goods increases, which indicates a lower number of produced varieties and a higher quantity of innovative technologies compared to the reference value. We conclude that the economy grows more in terms of quantity than with regards to quality.

The evolution is different in the tax scenario, as the payment of carbon taxes offers fewer investment possibilities to agents. With similar mechanisms of anticipation and adaptation, research and development activities decline as patent price decreases. Still, standard investments improve, because interest rates slightly drop over time. Anticipation of decreased R\&D activities and increased energy prices forces firms to produce less, which negatively affects the growth rate. At the household level, agents anticipate more income, as increased tax revenue increases government resources, generating more social transfers available to households from governments. Other models, such as the G-Cubed model (McKibbin and Wilcoxen, 1995), assume that households are the direct owners of permit revenues, even if firms decide on the use of permits. Under this assumption, the impact is stronger on households, as households receive all permit revenues. In our simulations, the effect of increased consumption on the economy is positive but not strong enough to enhance production, investments and, finally, economic growth.

At the sectoral level, the net permit sellers on the free permit market include the electricity, glass, cement and paper industries; they have the lowest abatement costs among eligible sectors as well as record gains on the market. The remaining sectors, namely, refineries and metallurgy, are net buyers of polluting rights. Despite severe constraints set on its emissions, electricity production grows due to the low emissions coefficients of its output, as so does glass and cement production due to the significant potential in energy efficiency of these sectors. Abatement increases the income generated by selling permits, which encourages investments in both standard and development forms of capital goods and thus results in substitution among possible energy inputs as well as diffusion of technological knowledge.

In contrast, when permits are auctioned, all producers are affected, since all producers are buyers on the market. Changes in fiscal indicators due to carbon permit auctions creates a strong signal across all sectors, including those that are not constrained by the ETS policy. Increased production prices lower demand and sector investment capacity, which directly harms demand for development goods (-1.3\%) and output research (-0.04\%).

The positive impact of environmental regulation is that increased production costs require firms to revise their production technologies, thereby becoming more resource-efficient. The new policy creates incentives to invest in development technologies. This encourages a better allocation of inputs as well as productivity gains due to spillover effects. This, of course, means that there have existed more efficient input allocations that were simply not exploited before the introduction of the new regulation. This supports Porter's hypothesis (1991) that postulates that environmental regulation can ensure more efficient resource allocations as producers invest more in new technologies aimed at reducing their energy inefficiencies.

- The implementation of a permit market forces firms to reorganise their intermediate consumption of resources in favour of non-polluting inputs, as electricity, capital and labour. This benefits overall demand $(0.32 \%)$, the real GDP $(0.06 \%)$, household consumption $(0.13 \%)$, and economic growth $(0.15 \%)$. Still, certain limitations remain, as growth does not systematically increase when environmental regulation hardens. Tests of higher regulatory constraints show an inverse relationship between environmental policy and economic growth. 
- The carbon tax scenario does not substantiate the Porter hypothesis: economic growth ($0.3 \%)$, the real GDP $(-0.01 \%)$ and aggregate input $(-0.84 \%)$ all drop. Moreover, employment decreases $(-0.07 \%)$, and investment possibilities shrink. The nature of the underlying environmental regulations explains the divergence between these two scenario results (Ambec and Barla, 2001; Baker et al., 2008). The implementation of a tax introduces a certain level of rigidity, because its level is exogenously set for all sectors despite different abatement possibilities. Alternatively, the permit price is computed endogenously as a function of abatement costs that may differ across sectors. Flexibility is reinforced in the latter case by the fact that initial permit allocation is implemented by grandfathering.

At the household level, welfare diminishes in the permit case (-0.13\%) and improves in the tax scenario $(0.58 \%)$. Imposing an environmental constraint generally enhances positive social costs, while individual welfare declines if no compensatory measures are applied. Our simulations show an opposite relationship in the tax scenario, mostly because improvements in consumption resulting from individual increased income grow with an increase in social transfers, as explained above. This result may also be rather surprising with regards to the permit scenario, because the variation in consumption is positive in the terminal period. The counterintuitive finding that welfare improves under a tax scenario but declines in the permit scenario is rather explained by shifts in the main indicators that comprise welfare.

Figure 2. The evolution of household consumption $(\%$, reference $=0)$
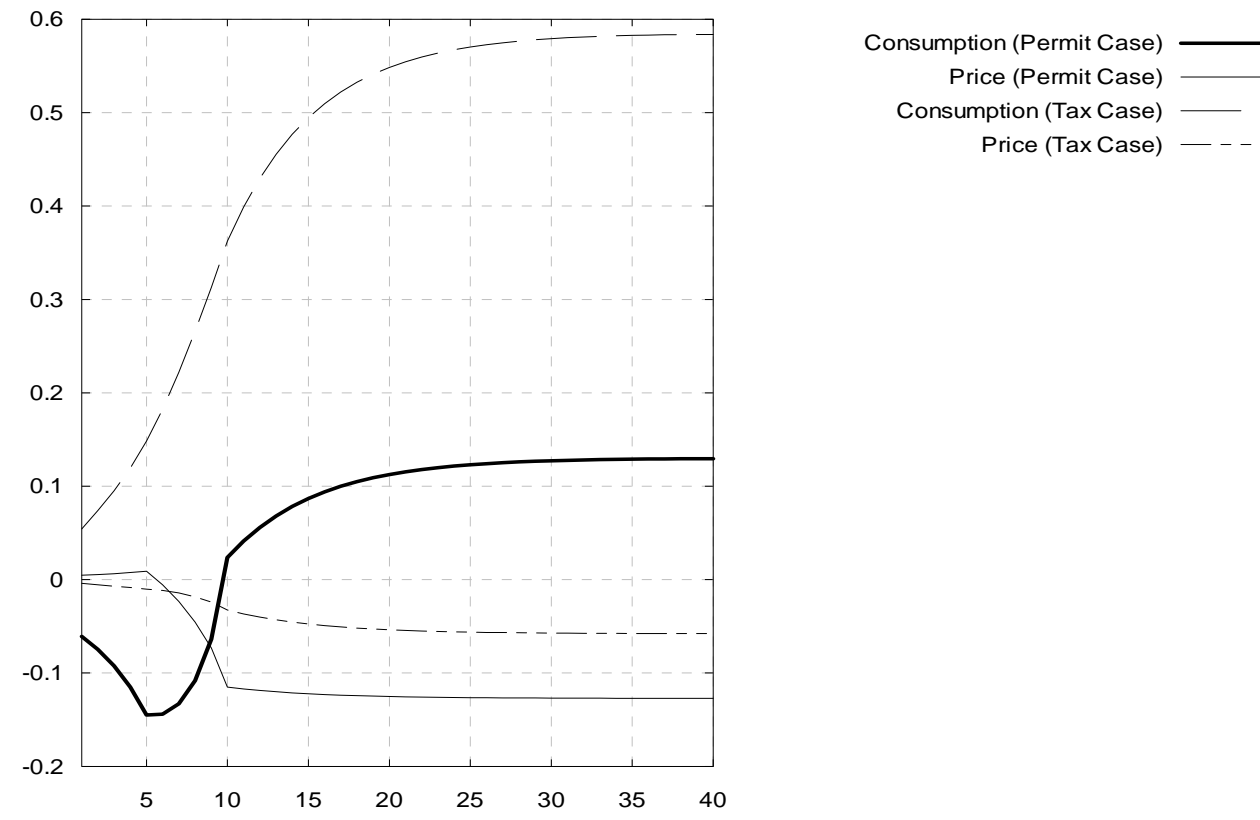

Welfare is measured by intertemporal consumption income discounted by the interest rate. Understanding the trade-off between long-term and short-term consumption is necessary for evaluating efforts to reduce emissions within an intertemporal framework. This approach is commonly adopted in the climate change literature, and it actualises future income in order to give a present value to financial flows occurring in the future. Discounting with regards to the value of the actualisation rate is one of the most controversial issues in environmental economics, particularly after the publication of the Stern Review (Stern, 2007; Nordhaus, 2007; Tol and Yohe, 2009). Low discount rates tend to accord more value to future generations as well as encourage investments, even relatively inefficient investments. Higher future values relate to higher rates of time preference and higher values of consumption, thus generally leading to inefficiencies in selecting investment policies. The present research 
applies the usual exponential discounting form $1 /(1+r)^{t}$ to balance between present and future well-being. The values employed to generate the welfare indicator include $5.7 \%$ for the interest rate and $5.6 \%$ for the time preference. These values are close to those used by Goulder and Schneider (1999) and Lau et al. (2002), but they are higher than the Nordhaus (2007) calibration, which set the interest rate at $4.5 \%$ and the time preference at $3 \%$.

We next explain the effects of the main variables, including consumption, individual income and discounting rate, on welfare.

According to the functions that describe consumer behaviour, two intratemporal trade-offs take place simultaneously: a trade-off between leisure and consumption, on the one hand, and a trade-off between saving and consumption, on the other hand. The first intratemporal tradeoff is done in favour of consumption; saving has an inverse propensity rate with regards to consumption, and so a decrease in consumption at the beginning of an interval translates into an increase in savings during this period as a response to growth investment needs. The evolution of consumption also implies an intertemporal trade-off between short-term and long-term consumption. Since consumers anticipate changes in prices, consumption paths are inversely correlated to the trajectory of prices changes. In the permit scenario, for instance, individuals anticipate a decrease in the long-term aggregate price and make a trade-off that favours long-term consumption. It is worth noting that price and growth trajectories are somewhat similar over time, as both increase until the shock period and then decrease during the shock (2008-2012). As growth slows down, savings habits are changed to so as to increase consumption, which further decreases consumer prices. Increased consumption encourages growth despite declines in household savings, partly because this increases the public deficit and partly because there is a growth self-perpetuating tendency that derives from the diffusion of spillover effects.

The household income variation tends to zero in the permit scenario, but it increases in the tax scenario, mostly due to social transfers' variations. Transfers vary positively in the tax scenario, since the state collects environmental tax revenues. In contrast, the permits trade does not generate fiscal assets to the state budget, and consequently, social transfers are lower as compared to the tax scenario. Intertemporal household income also increases in the tax scenario, because the discounting rate decreases, appreciating individual income. The differentiation in interest rate variations between the two scenarios shows divergent growth trajectories: enhanced growth in the permit scenario requires more investment $(0.29 \%)$ as compared with the tax scenario (-0.07\%), which implies a different evolutionary trajectory for the discounting rate.

A decreased interest rate in the tax scenarios implies a higher decrease in household savings ($0.8 \%)$ than in the permit scenario $(-0.5 \%)$; this effect is reinforced by the deflationary impact of the policy, as the consumption is encouraged detrimental to saving.

If consumption is used as the welfare measure, both policies would show positive effects in the terminal period of simulation. But this indicator does not take into account the transitory impacts of the policy, such as the decrease in consumption before the shock in the permit scenario. Dynamic, intertemporal accounting of the evolution of individual consumption income appears more appropriate to our analysis.

From an energy and environment perspective, both carbon policies decrease emissions levels, but with different energy trends. 
The permit market stimulates energy demand (2.3\%), consequently to increased economic growth that induces an energy rebound effect. The energy demand increases mostly for electricity and oil. One must notice that the elasticities of substitution favour electricity as new nuclear reactors will begin to operate, ensuring about $5-7 \%$ of the actual electricity supply. The electricity price increase is the consequence of a rise in energy input prices; the primary energy structure is $14 \%$ coal, $17 \%$ oil and $18 \%$ gas. Coal production drastically drops despite small changes in production price; this is a demand-effect, due to coal high emission coefficients.

The carbon tax decreases overall activities, but it leads also to more efficiency regarding the use of energy, as the energy per unit of GDP decreases (-5.9\%). All energy resources decrease under this scenario due to the increase in energy prices, on the one hand, and reduced production activity in all sectors, on the other hand. In this way, the price of gas drops, but its demand declines as the result of output contractions across all sectors. This is explained by the high demand for gas relative to the total primary energy demand (34\%). Similarly, electricity demand decreases, despite its low emission coefficient.

Table 2. The volume of consumption and the domestic production price by energy resource

\begin{tabular}{|c|c|c|c|c|c|c|c|c|c|c|}
\hline \multirow{2}{*}{\begin{tabular}{|c|} 
Energy \\
Electricity
\end{tabular}} & \multicolumn{5}{|c|}{ Tax } & \multicolumn{5}{|c|}{$\begin{array}{c}\text { Permits } \\
\text { Consumption Production Imports Exports Price }\end{array}$} \\
\hline & -4.3 & -4.4 & 6.3 & -4.4 & 3.9 & 6.7 & 6.7 & 9.3 & -1.0 & 0.6 \\
\hline Coal & -19.4 & -19.7 & -18.6 & -1.3 & 0.6 & -22.0 & -22.0 & -21.8 & -0.4 & 0.0 \\
\hline Oil & -2.3 & -2.6 & -1.6 & -1.6 & 0.9 & 0.2 & 0.0 & 0.6 & -0.5 & 0.2 \\
\hline Gas & -5.5 & -5.3 & -5.5 & -0.6 & -0.1 & -1.3 & -1.3 & -1.3 & -0.2 & -0.1 \\
\hline
\end{tabular}

Decreased coal consumption is a response to the constraining policy; as a result, it reduces emissions and changes the structure of the energy balance. However, it also potentially introduces national dependency on energy imports. Since coal represents Romania's main, most abundant energy resource in the long-term, the current coal-based national strategy is justified; it encourages coal-fired power stations and provides them with carbon geological storage technologies, as Romania has the potential to store carbon underground. However, if these projects are deemed socially accepted, they would probably not be effective until 2020. Under the permit scenario, the country's energy dependency as the ratio of energy imports to the total energy consumption deteriorates as domestic prices increase. In the tax scenario, the country's energy dependency decreases due to contractions in production activities.

Under both policies, exports decrease for all four energy sources modelled here because of depreciation in the national currency. Recall that both imported and domestic inputs are subject to carbon constraints. An imperfect substitution of imported energy resources for domestic ones is the result of the comparative advantage between domestic and world prices. But world prices are assumed to be fixed, as Romania is modelled as a small open economy. With regards to import structure, we notice an increase in the volume of electricity, but the country does not lose its status as a net exporter of electricity. Still, this result contradicts one of the national strategic goals to expand the electricity network as well as export capacities related to renewable or coal resources. If these scenarios do not follow long-term national strategy, complementary measures should be adopted in order to support the electricity sector. This may include fiscal measures or R\&D subsidies in the short- or medium-term and political measures, such as implementing CCS technologies through international cofinancing. 
We assume that economic growth through development technologies allows sectors to evolve at the global growth rate. If particular specifications are adopted on innovative abatement techniques, energy prices should decrease according to their degree of incorporation. This would imply a differentiation between the effects of fundamental research on sector productivity and the effect of environmental research on the efficiency gains of agents. Results should not be considerably different, as the energy and environmental programs represent only about $4.9 \%$ of total R\&D expenses (NIS, 2006b). The modelling framework for fundamental research has been adapted in studies of transition countries that have an absorption capacity for the technological progress; still, results may be systematically low due to the aggregation of specific sector innovations with fundamental research.

\subsection{Endogenous versus exogenous growth}

The integration of the endogenous growth mechanism is usually highlighted through comparison with a scenario that includes exogenous progress. A similar comparison is carried out here by simulating two versions of our model, with one based on exogenous growth and the other based on endogenous growth. The analysis focuses on results obtained from the tax and permit scenarios in the terminal period of simulation in order to avoid transitory effects. The welfare indicator is the only variable that accumulates these transitory impacts.

The framework built under the premise of exogenous growth assumes that the economy grows at a fixed rate indicated by the growth of the active population. This allows us to analyse substitution effects as response of the economy to environmental regulation (Exo). When the system evolves endogenously, spillover effects are added to substitution impacts (Endo). Comparing these two cases allows us to better describe the effects of technological diffusion generated by the research sector. Several outcomes are noteworthy.

1) Variations between the two versions are very close for most of the indicators in the permit scenario. However, the situation is more nuanced in the tax scenario, as the carbon signal is stronger and impacts are more pronounced (see Table 3). Using a similar approach, Nordhaus (2002) tested cases of endogenous and exogenous technological progress and showed that substitution is responsible for 99\% of changes occurring in the system. This argument substantiates the similarities we see in our cases across endogenous and exogenous growth. To Nordhaus's (2002) theoretical insights, we add the empirical fact that the investment innovative activities in Romania in 2003 were relatively weak ( $0.39 \%$ of the GDP), and thus, it is unlikely to have a major impact at the aggregate level. Similarly, Gillingham et al. (2008) argued that endogenising technical change may not greatly affect mitigation costs if other, relative prices do not change substantially.

Table 3. Sector results from environmental instruments implementation (\%)

\begin{tabular}{|c|c|c|c|c|c|c|c|c|c|c|c|c|}
\hline \multirow{3}{*}{ Sector } & \multicolumn{6}{|c|}{ Permit Market (Grandfathering) } & \multicolumn{6}{|c|}{ Taxation (Permit Auctioning) } \\
\hline & \multicolumn{2}{|c|}{ Production } & \multicolumn{2}{|c|}{\begin{tabular}{|c|} 
Investment \\
\end{tabular}} & \multicolumn{2}{|c|}{ Permits $\left(10^{3}\right)$} & \multicolumn{2}{|c|}{$\begin{array}{c}\text { Production } \\
\text { cost }\end{array}$} & \multicolumn{2}{|c|}{ Investment } & \multicolumn{2}{|c|}{ Permits $\left(10^{3}\right)$} \\
\hline & Endo & Exo & \begin{tabular}{|c|} 
Endo \\
DvK StandK
\end{tabular} & Exo & Endo & Exo & Endo & Exo & \begin{tabular}{r|} 
Endo \\
DvK \\
StandK \\
\end{tabular} & Exo & Endo & Exo \\
\hline Electricity & 6.7 & 6.72 & $\begin{array}{ll}7.78 & 8.17\end{array}$ & 8.23 & -0.55 & -1.13 & -4.41 & -4.44 & $\begin{array}{|ll|}0.95 & 2.54 \\
\end{array}$ & 2.41 & 41399.18 & 41399.8 \\
\hline Coal & -22.01 & -22.01 & $-22.01-21.73$ & -21.69 & 0 & 0 & -19.72 & -19.72 & $-19.82-18.56$ & -18.64 & 0 & 0 \\
\hline Oil & -0.03 & -0.02 & $0.21 \quad 0.58$ & 0.63 & 812.71 & 812.81 & -2.62 & -2.64 & $-2.08 \quad-0.54$ & -0.65 & 3857.83 & 3857.48 \\
\hline Gas & -1.28 & -1.28 & $-1.59-1.23$ & -1.19 & 0 & 0 & -5.28 & $\mid-5.28$ & $-6.61 \quad-5.14$ & -5.24 & 0 & 0 \\
\hline Metallurgy & $|-0.64|$ & -0.62 & $0.8 \quad 1.16$ & 1.22 & 1464.29 & 1465.04 & $\mid-2.75$ & $|-2.77|$ & $\begin{array}{|ll|}2.55 & 4.17\end{array}$ & 4.05 & 8784.69 & 8783.36 \\
\hline
\end{tabular}




\begin{tabular}{|l|c|c|cc|c|c|c|c|c|cc|c|c|c|} 
Glass & 0.04 & 0.06 & -0.58 & -0.22 & -0.17 & -252.39 & -252.4 & -1.38 & -1.43 & -0.7 & 0.87 & 0.74 & 231.72 & 231.77 \\
Cement & 0.16 & 0.17 & -0.97 & -0.61 & -0.57 & -1897.46 & -1897.71 & -1.2 & -1.22 & 1.02 & 2.61 & 2.51 & 1777.54 & 1778.48 \\
Paper & -0.15 & -0.12 & -0.39 & -0.04 & 0.01 & -126.61 & -126.62 & -1.16 & -1.22 & -0.95 & 0.6 & 0.5 & 228.25 & 228.32 \\
Chemistry & -0.26 & -0.24 & 0.03 & 0.39 & 0.45 & 0 & 0 & -1.48 & -1.52 & -0.07 & 1.5 & 1.37 & 0 & 0 \\
Transport & -0.12 & -0.1 & -0.3 & 0.06 & 0.1 & 0 & 0 & -0.48 & -0.54 & -1.47 & 0.07 & -0.03 & 0 & 0 \\
Agriculture & 0 & 0.04 & -0.3 & 0.06 & 0.12 & 0 & 0 & 0.08 & -0.01 & -1.25 & 0.31 & 0.19 & 0 & 0 \\
Constructions & 0.38 & 0.36 & 0.19 & 0.55 & 0.55 & 0 & 0 & -0.24 & -0.2 & -1.38 & 0.17 & 0.16 & 0 & 0 \\
Services & 0.05 & 0.07 & -0.16 & 0.2 & 0.24 & 0 & 0 & -0.06 & -0.1 & -1.28 & 0.27 & 0.17 & 0 & 0 \\
Other activities & -0.15 & -0.12 & -0.3 & 0.05 & 0.11 & 0 & 0 & -0.71 & -0.76 & -1.63 & -0.09 & -0.2 & 0 & 0
\end{tabular}

Table 3 shows sector results based on the two different carbon policies in terms of production, investment and carbon-burden sharing. Sectors that are not eligible for permit trade record zero gains or costs on the market and are only indirectly affected by the constraining policy applied to other agents. All sectors reduce their emissions, except agriculture and construction under the permit scenario due to a demand-effect. Among non-eligible sectors, energyintensive sectors such as chemistry, transport and 'other activities' are most impacted, as the carbon price-signal is strong enough to influence their input preferences.

Investments are implemented under exogenous growth using standard physical capital, while under endogenous growth, investments are split between standard and development capital. This increases the substitution possibilities between capital and energy as well as enhances spillover effects that may generate innovative technologies.

2) The permit market simulation shows an improvement in welfare under exogenous growth but a decrease in welfare under endogenous growth. That is, the increased value of the discount rate under endogenous dynamics depreciates the intertemporal income of households. Yet, consumption increases at a slower rate. This is because the same environmental constraints in fact represent more stringent constraints in the exogenous growth scenario as compared to the endogenous growth scenario, as no spillover effects are generated. This implies more structural changes under exogenous growth than under the endogenous scenario, which in turn encourages overall production activities as well as stimulates the GDP and aggregate output. This situation benefits households, as they own the production factors. Income from both capital and labour increases and thus induces higher individual income variation.

In the tax scenario, welfare varies positively with growth in both cases, though in a higher proportion under endogenous growth. Decreased growth diminishes the discount rate and thus depreciates the intertemporal income as compared with the reference case. A tax value that equals the auctioned permits price is slightly higher under endogenous growth in which productive activities decrease less and require more pollution permits; therefore, state income increases more due to environmental fiscal revenues and social transfers rise more under a situation of endogenous growth rather than under exogenous growth.

3) Investment accounts show divergent effects depending on the environmental policy. Capital volume is higher under endogenous growth in the permit market scenario, but it is lower under endogenous growth in the tax scenario.

In the permit scenario, investments increase with regards to both development and standard capital goods. Despite price increases, demand for development goods slightly improves due to spillover effects generated by positive variations in the growth rate. An opposite effect is seen in the tax scenario, in which demand for development goods decreases, generating fewer spillover effects. Improved R\&D output could be obtained through state intervention aimed at 
sustaining investments in development capital goods. A higher level of investment in conventional capital diminishes investments in the research; this is a situation that the literature has described as a "crowding out" effect (Nordhaus, 2002). The magnitude of a crowding out effect depends on the relative prices of standard and development goods and on elasticity of substitution between these two forms of investment. This issue raises the debate on whether conventional capital and development technology are substitutable or complementary (Buonanno et al., 2003).

Under the free permit market simulation, the demand for development goods increases in sectors such as electricity, refineries, metallurgy, chemistry and constructions, but it drops in the remaining sectors. Note that sectors that diminish their activities (i.e., coal, gas and paper) invest less in capital goods, but sectors that increase their activities and still lower their demand for development goods benefit from the investments made by their suppliers. This is the case for two energy-intensive sectors, glass and cement, which undergo an increase in their demand for electricity and thus benefit from the investments in innovation made by the electricity sector. A higher variation in development capital is recorded in the electricity sector, which is the main energy supplier in the simulated economy. All sectors take advantage of improved competitiveness and are thus less likely to invest in development goods, as they benefit from the spillover effects generated by the electricity sector. In a similar context, Buonanno et al. (2003) showed that spillover effects reduce producer incentives to invest and encourage a "free-riding" attitude, since producers benefit from the innovations of their suppliers.

Under the tax simulation, these implications are not valid, since on the one hand, a reduced growth rate limits the spillover effects and, on the other hand, fewer resources in all sectors diminish investment possibilities.

4) The implementation of a permit market leads to price values close to the equilibrium price under endogenous and exogenous growth, although prices are slightly lower in the endogenous case (5.765 versus 5.766 euros). Even if the difference might appear insignificant, the total value of the market amounts to 13.1 M EUR, which corresponds to a volume of $2.28 \mathrm{M}$ traded permits. Any variation in the permit price is thus significant given the volume of trade.

The analysis focuses here on the qualitative impact of the permit trade under endogenous growth. The volume traded under the exogenous growth scenario is greater as compared to endogenous growth. Considering the increased activity under exogenous growth, the rise in the demand for polluting rights appears justified. Still, the abatement cost per unit of GDP is higher in the endogenous case. This result strengthens our finding that spillover effects reduce the incentive to invest in order to improve production technologies. This conclusion can be further extended: in fact, spillover effects negatively impact the incentive to reduce pollution. As endogenous growth provides additional productivity gains and involves fewer structural changes, the permit supply is lowered in all sectors.

5) Both cases assume that environmental regulation begins in the year 2008 and that it is announced so that households can anticipate policy changes and adapt their behaviours, as explained above. Assuming exogenous growth, the long-term effects are similar whether the policy is announced or not. By contrast, the results are different under endogenous growth depending on whether the policy is announced or not. When the policy is announced, the long-term growth rate changes, affecting variables that are deflated with the growth rate. Consequently, the transition to a steady state is facilitated by these dynamics and is costless from both social and economic point of view (Goulder, 2004). While economic growth is 
higher in this case, it negatively affects permit prices, as the supply of permit supply is diminished. Thus, the endogenous and exogenous growth versions of our model differ in this perspective, and it appears that the anticipations of agents have a more significant impact under the endogenous growth scenario than under exogenous growth.

\section{Conclusions and policy recommendations}

This research simulates the implementation of a $\mathrm{CO} 2$ tradable permit market in Romania in order to estimate the marginal abatement costs and the long-term economic impacts. An intertemporal general equilibrium model is applied using a dynamic approach based on the exogenous evolution of the active population and endogenous technological progress. The model structure assumes an infinitely-lived representative household, as in the Ramsey model (1928), and describes the innovation mechanism through which production and diffusion of knowledge occur, as in the Romer model (1990). Endogenous dynamics have sparked a large debate from both a modelling and a calibration point-of-view (Qayum, 2005). This is due to uncertainty regarding the validity of setting growth determinants. Although we have not clarified this complex issue, our research aims to better understand the relationship between fundamental innovation and marginal abatement cost in a carbon-constrained economy. An optimisation criteria-based approach allows us to estimate the level of carbon signal according to economic efficiency principles. This approach avoids the transfer of carbon prices onto the consumer as well as speculative actions on the permit market. Since economic evaluations are one of the many steps involved in policy-making processes, the following conclusions should be considered a starting point for defining short-term climate policies rather than a predictive description of the long-term evolution of the Romanian economy.

Regarding the choice of market instrument upon which to base carbon policy, our model simulations show that implementing a permit scheme encourages economic growth because of the flexibility to abate emissions when it is relatively low-cost and because of the free distribution of tradable quotas. In contrast, introducing a carbon tax has a punishing impact on productive activities and economic growth, as it allocates fewer resources to sectors in order to invest in innovation. If a carbon tax is adopted, complementary measures should be adopted to recycle the collected revenue back into the economy, for instance, by reducing the payroll taxes of enterprises so as to benefit both producers and consumers. Recycling the tax product by lump-sum transfers to households would be less efficient (Goulder, 1994); as shown in our model, increased social transfers have had a positive impact on consumption but a limited effect on overall production.

Consumer effects show an increase in individual consumption under both tax and permit policies, but these results vary regarding intertemporal welfare due to the different evolution of the discount rate. With regard to the energy policy, one notices a decrease in the volume of polluting resources and a rise in the consumption of electricity. Still, reducing the production of coal is not in line with Romania's national strategy aimed at energy independency. Thus, this research supports clean coal projects, such as carbon capture and storage implementation, as a complement for investments in renewable-based power plants. Our results show that the tax policy is more appropriate for regulating energy use, but its decreased growth suggests that these positive effects could be due more to contractions in productive activities than to the efficient use of resources. As a short-term policy, the use of permits may be more appropriated during the transition period, while the tax policy may be an appropriate middleterm or long-term strategy if it includes compensatory measures designed particularly for eligible sectors. 
However, both policies have a negative impact on the public deficit that is strongly increasing, indicating that additional financing is necessary to ensure the financial health of the Romanian economy. Thus, public intervention remains essential, both in terms of regulation and financial support. The interaction between the two market inefficiencies, namely negative externalities due to pollution and positive externalities due to research spillover, requires a mix of public policies related to carbon targets and to aids to innovation by supporting the research and development sectors. The small difference between the results under endogenous and exogenous growth is the consequence of the low level of financial and human resources involved in Romanian R\&D activities. In line with the Lisbon Agenda objectives that allow 3\% of the EU GDP to R\&D in 2010, Romania aims to increase research expenses from 0.4\% of GDP in 2006 to 1\% in 2010 (MEC, 2006). Our simulations support this policy aimed at eliminating barriers to knowledge diffusion as well as creating incentive for adopting innovative equipments, since a crowding out of R\&D investments tends to favour cheaper conventional technologies.

The role of knowledge diffusion is highlighted here by focusing on abatement costs: the spillover effects decrease these costs while increasing the ratio of abatement cost per unit of GDP. Still, technological diffusion has a positive impact on economic growth. The role of knowledge diffusion can further be explored by considering international spillover effects that emerge from transfers of technology between Romania and its trade partners in the EU. It may also be useful to consider various Kyoto mechanisms as joint implementation projects. With this regard, international spillover effects become the main argument for a global climate policy consisting in the development of clean mechanisms or joint implementation projects in developing countries. In this context, technological diffusion is a growth factor that compensates for negative externalities generated by polluting activities (Goulder and Mathai, 2000; Grubb and Kohler, 2002). Moreover, it is suggested that mechanisms of technological transfer represent one of lowest-cost abatement options (Rao et al., 2006).

Contrary to the idea that countries in transition have growth priorities that overshadow their environmental concerns, this research shows that the two goals are not incompatible, because environmental policy can generate benefits that fuel economic growth processes. The tax and trade of emissions permits are the necessary tools for encouraging and intensifying initiatives for and benefits of climate policies. Romania has already engaged in a direction that will allow the country to avoid negative economic and social outcomes in the long-term.

\section{Acknowledgements}

I am very grateful to Daniel Thery and the two anonymous referees who provided numerous constructive comments and critical feedback, which led to the significant improvement of the paper. Responsibility for ideas expressed and any remaining errors are my own.

\section{References}

Aghion, P., Howitt, P., 1992. "A Model of Growth through Creative Destruction” Econometrica, 60(2): 323-351.

Ambec, S., Barla, P., 2001, "Productivité et réglementation environnementale: une analyse de l'hypothèse de Porter”, Working Paper INRA-ESR n²3, Grenoble.

Armington, P.S., 1969, "A theory of demand for products distinguished by place of production”, IMF Staff Papers 16: 159-178. 
Baker E., Clarke L., Shittu E., 2008, “Technical change and the marginal cost of abatement”, Energy Economics 30(6): 2799-2816.

Barro, R. J., Sala-i-Martín, X., 1995, Economic Growth. New York, McGraw-Hill.

Beaumais, O., 1995, "Une réinterprétation des politiques de l'environnement par les modèles”, PhD Thesis Université de Paris I Panthéon - Sorbonne.

Böhringer, C., Löschel, A., Rutherford T.F., 2007, "Decomposing the integrated assessment of climate change”, Journal of Economic Dynamics \& Control, 31: 683-702.

Bohringer, C., Rutherford, T.F., 1997, "Carbon taxes with exemptions in an open economy: a general equilibrium analysis of the German tax initiative", Journal of Environmental Economics and Management, 32: 189-203.

Brooke, A., Kendrick, D., Meeraus, A., Raman, R., 1998, GAMS: a user's guide, GAMS Development Corporation, Washington.

Buonanno, P., Carraro, C., Galeotti, M., 2003, "Endogenous induced technical change and the cost of Kyoto", Resource and Energy Economics 25(1): 11-34.

Burniaux, J.-M., Nicoletti, G., Oliveira-Martins, J., 1992, "GREEN: a Global Model for Quantifying the Costs of Policies to Curb CO2 Emissions”, OECD Economic Studies, 19: 49-92.

Lee, H., Oliveira-Martins, J., van der Mensbrugghe, D., 1994, The OECD GREEN model: an updated overview, Working Paper No. 97, OECD Development Centre.

Cass, D., 1965, “Optimum growth in an aggregative model of capital accumulation”, Review of Economic Studies, 32: 233-240.

Gillingham K., Newell R.G., Pizer, W.A., 2008, "Modeling endogenous technological change for climate policy analysis”, Energy Economics 30: 2734-2753.

Goulder, L.H., 2004, Induced Technological Change and Climate Policy, Pew Center on Global Climate Change Report, Washington DC.

Goulder, L.H., 1994, "Environmental taxation and the double dividend: a reader's guide”, NBER Working Paper No. 4896.

Goulder, L., Mathai, K., 2000, "Optimal CO2 abatement in the presence of induced technical change”, Journal of Environmental Economics and Management, 39: 1-38.

Goulder, L.A., Schneider, S.H., 1999, "Induced technological change and the attractiveness of CO2 abatement policies”, Resource and Energy Economics, 21: 211-253.

Grubb, M., Kohler, J., 2002, “Technical change and energy/environmental modelling”, Technology Policy and Environment, OECD.

Grossman, G. M., Helpman, E., 1991, “Endogenous Product Cycles”, The Economic Journal 101: 1214 - 1229.

European Commission, 2008, 'Proposal for a Directive of the European Parliament and of the Council amending Directive 2003/87/EC so as to improve and extend the greenhouse gas emissions allowance trading system of the Community', $\operatorname{COM(2008)~} 16$ final 2008/0013 (COD), Brussels.

European Commission, 2007, Emissions trading: Commission approves Romania's national allocation plans for 2007 and 2008-2012, IP/07/1612, Brussels.

European Commission, 2003, Directive 2003/87/EC of the European Parliament and the Council of 13 October 2003 establishing a scheme for greenhouse gas emission allowance trading within the Community and amending Council Directive 96/61EC.

Ellerman, A.D, Decaux, A., 1998, Analysis of Post-Kyoto CO2 Emissions Trading Using Marginal Abatement Curves, MIT Joint Program on the Science and Policy of Global Change, Report 40, Cambridge MA.

Ha-Duong, M., Grubb, M., Hourcade, J.C., 2004, “Influence of socioeconomic inertia and uncertainty on optimal CO2-emission abatement”, Pre- and Post-Print documents halshs-00002452_v1, HAL, CCSD. 
Kemfert, C., Welsch, H., 2000, "Energy-Capital-Labor Substitution and the Economic Effects of $\mathrm{CO}_{2}$ Abatement: Evidence for Germany”, Journal of Policy Modelling 22(6): 641660.

Kohler, J., Grubb, M., Popp, D., 2006, “The transition to endogenous technical change in climate-economy models: a technical overview to the innovation modeling comparison project”, The Energy Journal, Special issue: Endogenous Technological Change and the Economics of Atmospheric Stabilisation: 17-55.

Koopmans, T.C., 1965, “On the concept of optimal economic growth”, in The Econometric Approach to Development Planning, Amsterdam.

Lau, M.I., Pahlke, A., Rutherford, T.F., 2002, “Approximating infinite-horizon models in a complementarity format: a primer in dynamic general equilibrium analysis”, Journal of Economic Dynamics and Control, 26: 577-609.

Lucas, R., 1988, "On the mechanics of economic development”, Journal of Monetary Economics, 22 : 3-42.

Mage, S., 2004, "Ouverture commerciale et croissance : une analyse en équilibre général appliqué au cas de la Pologne”, PhD Thesis, Université de Paris Dauphine.

Manne, A.S., Richels, R.G., 2002, "The impact of learning-by-doing on the timing and costs of CO2 abatement”, Working Paper, Stanford University, CA.

McKibbin, W.J., Wilcoxen, P.J., 1995, "The Theoretical and Empirical Structure of the GCubed Model”, Discussion Papers 118, Brookings Institution International Economics.

Nadiri, M.I., Prucha, I.R., 1996, "Estimation of the Depreciation Rate of Physical and R\&D Capital in the U.S. Total Manufacturing Sector", Oxford University Press, 34(1): 43-56.

NIS, National Institute of Statistics, 2006a, Conturi Nationale 2002-2003, Bucharest.

NIS, National Institute of Statistics, 2006b, "Cercetare-dezvoltare si inovare", Anuarul Statistic al Romaniei, Bucharest.

Nordhaus,W.D., 2007a, "Critical assumptions in the Stern Review on climate change", Science, 317: 201-202.

Nordhaus,W.D., 2007b, The Challenge of Global Warming: Economic Models and Environmental Policy. Yale University.

Nordhaus, W.D., 2002, “Modeling Induced Innovation in Climate Change Policy”, in A. Grubler, N. Nakicenovic et W.D. Nordhaus (eds.), Technological Change and the Environment, Washington, D.C.: Resources for the Future.

Nordhaus, W.D., 1999, "Modeling induced innovation in climate policy change in a puttysemi-putty vintage world”, GEM-E3 Working Paper.

Nordhaus, W.D., 1992, “An optimal transition path for controlling greenhouse gases”, Science, 258: 1315-1319.

Otto V.M., Loschel A., Reilly J., 2008, "Directed technical change and differentiation of climate policy”, Energy Economics 30: 2855-2878.

Piazolo D., 2000, "Poland's membership in the European Union: an analysis with a dynamic CGE model”, LICOS, Discussion Paper 89.

Popp, D., 2002, “Induced innovation and energy prices”, American Economic Review, 92(1): 160-180.

Porter, M., 1991, “American’s Green Strategy”, Scientific American, 264: 168.

Qayum, A., 2005, "Endogenicity of economic growth models”, Technological Forecasting and Social Change 72: 75-84.

Ramsey, Y.F., 1928, “A Mathematical Theory of Saving”, Economic Journal, 38: 543-559.

Rao, S., Keppo, I., Riahi, K., 2006, "Importance of technological change and spillovers in long- term climate policy”, The Energy Journal, Special Issue: Endogenous Technological Change and the Economics of Atmospheric Stabilisation: 25-41. 
RME, Romanian Ministry of Environment and Water Management, 2006a, Politica energetica a Romaniei in perioada 2006-2009. Energie sigura, accesibila si curata pentru Romania, Bucharest.

RME, Romanian Ministry of Environment and Water Management, 2006b, Planul pentru promovarea eficientei energetice, Bucharest.

RME, Romanian Ministry of Environment and Water Management, 2006c, Romanian National Allocation Plan for the periods 2007 and 2008-2012, Bucharest.

RME, Romanian Ministry of Environment and Water Management, 2005, Report on demonstrable progress in implementing the Kyoto Protocol, Bucharest.

RMT, Romanian Ministry of Trade, 2006, Cresterea competitivitatii economice. Bucharest.

Romer, P.M., 1990, “Endogenous technological change”, Journal of Political Economy 98/5: 71-102.

Solow, R.M., 1956, “A Contribution to the Theory of Economic Growth”, Quarterly Journal of Economics, 70: 65-94.

Stanculescu, S.M., Berevoescu, I., 2004, 'Households, work and flexibility. Critical review of literature', Edited by Claire Wallace, Report 2000-2003.

Stern, N. et al., 2006, Stern Review: The Economics of Climate Change. HM Treasury, London.

Sue Wing, I., 2003, “Induced technical change and the cost of climate policy”. Joint Program on the Science and Policy of Global Change Report no. 112. Massachusetts Institute of Technology, Cambridge, MA.

Tietenberg, T., Grubb, M., Michaelowa, A., Swift, B., Zhang, Z.X., 1999, “International Rules for Greenhouse Gas Emissions Trading”, UNCTAD/GDS/GFSB/ Misc.6 United Nations, Genève.

Weyant, J.P., Olavson, T., 1999, "Issues in modeling induced technological change in energy, environment, and climate policy”, Environmental Modeling and Assessment, 4(2,3) : 6785.

Wigley, T., Richels, R., Edmonds, J., 1996, "Economic and Environmental Choices in the Stabilization of Atmospheric CO2 Concentrations”, Nature, 18: 240-243.

Tol, R.S.J., Yohe, GW., 2008, “The Stern Review: A deconstruction”, Energy Policy, doi:10.1016/j.enpol.2008.11.008. 
Appendix 1. The nested production function

(5)

(4)

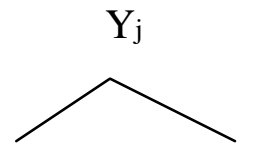

$\mathrm{KLEj}_{\mathrm{j}}$ Leontief $\mathrm{M}_{\mathrm{j}}$

(3)

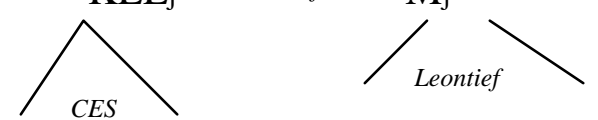

$\mathrm{Lj}$

$\mathrm{KEj}$<smiles>CCC(C)C</smiles>

$\mathrm{B} 5 \mathrm{j}$

$\mathrm{B} 14 \mathrm{j}$

(3)

(2)

$\mathbf{K d e v}_{\mathbf{j}} \mathrm{K}_{\mathrm{j}} \quad \mathrm{E}_{\mathrm{j}} \operatorname{dom}_{\mathrm{j}} \operatorname{impj}_{\mathrm{j}} . . . \ldots . \operatorname{dom}_{\mathrm{j}} \quad \mathrm{impj}$

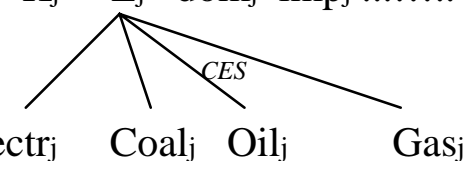

\section{Electrj Coal $_{j}$ Oil $_{j} \quad$ Gasj}

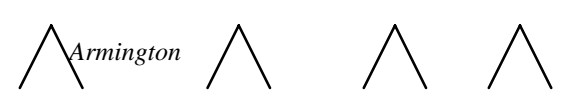

$\mathrm{CO}_{2}$ Permit /Tax

dom $_{j}$ impj domj impj domj impj domj impj

\section{Appendix 2. Model equations}

\section{Households}

$$
\begin{aligned}
& \operatorname{goodhd}_{j}=\operatorname{goodh}_{j} A 8_{j}^{\sigma c d i-1}\left(\alpha h_{j} \text { pcgood }_{j} / \operatorname{pcgoodd}_{j}\right)^{\sigma c d i_{j}} \\
& \operatorname{goodhi}_{j}=\operatorname{goodh}_{j} A 8_{j}^{\sigma c d i-1}\left[\left(1-\alpha h_{j}\right) \operatorname{pcgood}_{j} / \operatorname{pcgoodi}_{j}\right]^{\sigma c d i_{j}} \\
& \operatorname{goodh}_{j}=C_{t} A 9^{\sigma c-1}\left(\alpha c i d_{j} \cdot p c_{t} / \operatorname{pcgood}_{j, t}\right)^{\sigma c} \\
& \text { lorm }-l h_{t}=C_{t}\left[\beta \cdot p c_{t} /\left[(1-\beta)\left(1-\tau^{c s s}\right)\left(1-\tau^{i m p o}\right) w_{t}\right]\right]^{\sigma} \\
& \text { pcgoodd }_{j}=p p_{j}\left(1+\tau_{j}^{m c s}\right)\left(1+\tau_{j}^{t v a}+\tau_{j}^{a c c}+\tau_{j}^{s v b}\right) \\
& \text { pcgoodi }_{j}=t c_{t} \cdot p w \cdot\left(1+\tau_{j}^{\text {mcs }}\right)\left(1+\tau_{j}^{d d d}\right)\left(1+\tau_{j}^{t v a}+\tau_{j}^{a c c}+\tau_{j}^{s v b}\right) \\
& \operatorname{pcgood}_{j, t} \operatorname{goodh}_{j, t}=\operatorname{goodhd}_{j, t} \text { pcgoodd }_{j, t}+\operatorname{goodhi}_{j, t} \text { pcgoodi }_{j, t} \\
& p c_{t} C_{t}=\sum_{j} \text { pcgood }_{j, t} \text { goodh }_{j, t} \\
& T R S_{t}=\operatorname{SavH}_{t} / \text { props }-\left(S V D_{t}+p k_{t} \cdot K H_{t}+w_{t} \cdot l h_{t}+T R E H_{t}\right) \\
& S a v H_{t}=S V D_{t}+p k_{t} \cdot K H_{t}+\left(1-\tau^{c s s}\right)\left(1-\tau^{i m p o}\right) w_{t} l h_{t}+T R S_{t}+T R E H_{t}-p c_{t} C_{t}-T R H E_{t} \\
& C_{t+1}=C_{t}\left(\frac{1+r_{t+1}}{(1+\rho)(1+n)} \cdot \frac{p c_{t}}{p c_{t+1}}\right)^{\frac{\sigma}{\sigma \theta+1}}\left[\frac{1-\beta+\beta\left(\frac{\beta}{1-\beta} \frac{p c_{t}}{w_{t}\left(1-\tau^{c s s}\right)\left(1-\tau^{i m p o}\right)}\right)^{\sigma-1}}{1-\beta+\beta\left(\frac{\beta}{1-\beta} \frac{p c_{t+1}}{w_{t+1}\left(1-\tau^{c s s}\right)\left(1-\tau^{i m p o}\right)}\right)^{\sigma-1}}\right]^{\frac{\sigma \theta}{\left(1-\frac{1}{\sigma}\right)(\sigma \theta+1)}} \\
& \left(1+g_{T}\right)(1+n)=\left[\left(1+r_{T}\right) /(1+\rho)\right]^{\sigma /(\sigma \theta+1)}
\end{aligned}
$$

\section{Final good sector}




$$
\begin{aligned}
& \operatorname{cidom}_{i, j, t}=\operatorname{cin}_{i, j, t} A 1_{j}^{\sigma d i_{i}-1}\left(\alpha d i_{i} p c i_{i, j, t} / p p i n_{i, j, t}\right)^{\sigma d i_{i}} \\
& \operatorname{cim} p_{i, j, t}=\operatorname{cin}_{i, j, t} A 1_{j}^{\sigma d i_{i}-1}\left[\left(1-\alpha d i_{i}\right) p c i_{i, j, t} /\left(t c_{t} p w_{j} \cdot \tau_{i}^{m c s i}\right)\right]^{\sigma d i_{i}} \\
& \operatorname{cin}_{i, j, t}=E_{j, t} A 2_{j}^{\sigma e_{j}-1}\left(\alpha e_{i, j} p e_{j, t} / p c i_{i, j, t}\right)^{\sigma e_{j}}+\beta n e_{i} \alpha m i_{i, j} m_{j, t} \\
& E_{j, t}=K E_{j, t} A 3_{j}{ }^{\sigma k e_{j}-1}\left(\left(1-\alpha k_{j}\right) p k e_{j, t} / p e_{j, t}\right)^{\sigma k e_{j}} \\
& K_{j, t}=K E_{j, t} A 3_{j}{ }^{\sigma k e_{j}-1}\left(\alpha k_{j} p k e_{j, t} / r k_{j, t}\right)^{\sigma k e_{j}} \\
& K E_{j, t}=A 3_{j}\left[\alpha k_{j} K_{j, t}^{1-\frac{1}{\sigma k e}}+\alpha e n_{j} E_{j, t}^{1-\frac{1}{\sigma k e}}+\left(1-\alpha k_{j}-\alpha e n_{j}\right) A t_{t-1} /\left(1+g_{T}\right) b i v h t_{j, t}^{1-\frac{1}{\sigma k e}}\right]^{1 /\left(1-\frac{1}{\sigma k e}\right)} \\
& K E_{j, t}=K L E_{j, t} A 4_{j}{ }^{\sigma k l e_{j}-1}\left[\left(1-\alpha l_{j}\right) p k l e_{j, t} / p k e_{j, t}\right]^{\sigma k l e_{j}} \\
& L_{j, t}=K L E_{j, t} A 4_{j}{ }_{j}^{\sigma k l e_{j}-1}\left(\alpha l_{j} p k l e_{j, t} / p l_{j, t}\right)^{\sigma k l e_{j}} \\
& K L E_{j, t}=O_{j, t} / \alpha \text { kle }_{j} \\
& M_{j, t}=O_{j, t} / \alpha m_{j} \\
& O_{j, t}=\sum_{i} \sum_{j} \operatorname{cidom}_{i, j, t} I_{14}+\operatorname{goodh}_{j, t}+\operatorname{invdom}_{j, t}+\operatorname{dgd}{ }_{j}+x_{j, t} \\
& \operatorname{CO2} 2_{i, j, t}=\operatorname{coef}_{i, j} \operatorname{cin}_{i, j, t} \\
& \operatorname{pci}_{i, j, t} \operatorname{cin}_{i, j, t}=\operatorname{ppin}_{i, t} \operatorname{cidom}_{i, j, t}+t c_{t} \cdot p w_{j} \cdot \tau_{i}^{m{ }^{m s i}} \operatorname{cim} p_{i, j, t} \\
& p e_{j, t} E_{j, t}=\sum_{i} \beta e_{i} \operatorname{cin}_{i, j, t} p c i_{i, j, t} \\
& p m_{j, t} M_{j, t}=\sum_{i} \beta n e_{i} \operatorname{cin}{ }_{i, j, t} p c i_{i, j, t} \\
& p k e_{j, t} K E_{j, t}=K_{j, t} r k_{j}+E_{j, t} p e_{j, t}+\operatorname{pmon}_{t}\left(1-\tau_{t}^{s d}\right) A t_{t-1} /\left(1+g_{T}\right) b i v h t_{j, t} \\
& \text { pkle }{ }_{j, t} K L E_{j, t}=L_{j, t} p l_{j, t}+K E_{j, t} p k e_{j, t} \\
& p p_{j, t} O_{j, t}=p m_{j, t} M_{j, t}+K_{j, t} r k_{j}+E_{j, t} p e_{j, t}+L_{j, t} p l_{j, t}+p m o n_{t}\left(1-\tau_{t}^{s d}\right) A t_{t-1} /\left(1+g_{T}\right) b i v h t_{j, t} \\
& p l_{j, t}=w_{t}\left(1+d i f c \cdot \tau_{j}^{c s e}\right) \\
& \operatorname{ppin}_{i, t}=\sum_{j} p_{j, t}\left(1+\tau_{j}^{m c s}\right) I 14_{i, j}
\end{aligned}
$$

\section{Investment}




$$
\begin{aligned}
& \operatorname{invdom}_{j, t}=\operatorname{inv}_{j} A 5_{j}^{\sigma i n v d i_{j}-1}\left[\alpha i v_{j} \operatorname{pinvdi}_{j, t} /\left(p p_{j, t}\left(1+\tau_{j}^{m c s}\right)\right)\right]^{\sigma i n v d i_{j}} \\
& \text { invimp }_{j, t}=i n v_{j, t} A 5_{j}^{\sigma i n v d i_{j}-1}\left[\left(1-\alpha i v_{j}\right) \operatorname{pinvdi}_{j, t} /\left[t c_{t} \cdot p w\left(1+\tau_{j}^{m c s}\right)\right]\right]^{\sigma i n v d i_{j}} \\
& \text { inv }_{j, t}=\operatorname{InvtS}_{t} \cdot A 6^{\sigma i n v-1}\left(\alpha i v t_{j} \operatorname{pinv}_{t} / \operatorname{pinvdi}_{j, t}\right)^{\sigma i n v} \\
& \operatorname{pinvdi}_{j, t} \text { inv }_{j, t}=\left(1+\tau_{j}^{m c s}\right)\left(\text { invimp }_{j, t} t c_{t} \cdot p w_{j}+\operatorname{invdom}_{j, t} p p_{j, t}\right) \\
& \operatorname{pinv}_{t} \cdot \operatorname{Invt} S_{t}=\sum_{j} \operatorname{inv}_{j, t} \text { pinvdi }_{j, t} \\
& p k_{t}=\operatorname{pinv}_{t}\left(r_{t}+\delta\right) \\
& r k_{j, t}=p k_{t}\left(1+\tau_{j}^{i m p r}+\tau_{j}^{s v p}\right) \\
& \sum_{j} K_{j, t+1}=\operatorname{Invt} S_{t}+(1-\delta) /\left[(1+n)\left(1+g_{T}\right)\right] \sum_{j} K_{j, t} \\
& \sum_{j} K_{j, T}\left[(1+n)\left(1+g_{T}\right)-(1-\delta)\right]=\operatorname{InvtS_{T}}
\end{aligned}
$$

\section{Research sector}

$(1+g l t) w_{t} L r_{t}=\left(1+\tau^{s r}\right) \cdot \alpha r \cdot p r d_{t} A t_{t-1}$

$(1+g l t) p k \cdot K r_{t}=\left(1+\tau^{s r}\right)(1-\alpha r) \operatorname{prd}_{t} A t_{t-1}$

$(1+g l t) A t_{t}=\left(1+g_{t}\right) A t_{t-1}$

$g_{t}=\gamma L r_{t}^{\alpha r} K r_{t}^{1-\alpha r}$

$g_{T}=\gamma L r_{T}^{\alpha r} K r_{T}^{1-\alpha r}$

\section{Development sector}

$\operatorname{civ}_{j, t}=\operatorname{Eiv}_{t} A 7^{\sigma e_{j}-1}\left(\alpha \operatorname{civ}_{j} \text { peiv }_{t} / \operatorname{pciv}_{t}\right)^{\sigma e_{j}}+\beta 4_{j} \alpha d v_{j} \operatorname{Miv}_{t}$

$\operatorname{civdom}_{j, t}=\operatorname{civ}_{j, t} A 5^{\sigma i v d i_{j}-1}\left(\alpha i v_{j} p \operatorname{civ}_{j, t} / p p_{j, t}\right)^{\sigma i v d i_{j}}$

$\operatorname{civimp}_{j, t}=\operatorname{civ}_{j, t} A 5^{\sigma i v d d_{j}-1}\left(\left(1-\alpha i v_{j}\right) p \operatorname{civ}_{j, t} /\left(t c_{t} p w_{j}\right)\right)^{\sigma i v d d_{j}}$

$\operatorname{Kiv}_{t}=Y i v_{t} / \alpha v k ; \operatorname{Liv}_{t}=Y i v_{t} / \alpha v l ; M i v_{t}=Y i v_{t} / \alpha v m ; E i v_{t}=Y i v_{t} / \alpha v e$

$\operatorname{pciv}_{j, t} \operatorname{civ}_{j, t}=\operatorname{civdom}_{j, t} p p_{j, t}+\operatorname{civimp}_{j, t} t c_{t} p w$

$\operatorname{peiv}_{t}$ Eiv $_{t}=\sum_{j} \beta e n_{j} \operatorname{civ}_{j, t} p_{j, t} ; \operatorname{pmiv}_{t}$ Miv $_{t}=\sum_{j} \beta n e n_{j} \operatorname{civ}_{j, t} p p_{j, t}$

$p i v_{t} Y_{i v}=p k \cdot \operatorname{Kiv}_{t}+w_{t} \operatorname{Liv}_{t}+\operatorname{Eiv}_{t}$ peiv $_{t}+\operatorname{Miv}_{t}$ pmiv $_{t}$

pmon $_{t}=$ piv $_{t} /(1-1 / \sigma k e)$

pmon $_{t}=\operatorname{piv}_{t}+\pi u n_{t} / \sum_{j}$ bivht $_{j, t}$

Yiv $_{t}=\sum_{j}$ bivht $_{j, t} A t_{t-1} /\left(1+g_{T}\right)$

$S V D_{t}=\left(\right.$ pmon $\left._{t}-p b i v_{t}\right) A t_{t-1} /\left(1+g_{T}\right)$

$\operatorname{prd}_{t+1}+\pi u n_{t}=\left(1+r_{t}\right) p r d_{t} ; r_{T}=\pi u n_{T} / \operatorname{prd}_{T}$

\section{State}




$$
\begin{aligned}
& I S_{t}=\sum_{j}\left[\tau_{j}^{c s e} w_{t} \cdot l_{j, t}+\left(\tau_{j}^{i m p r}+\tau_{j}^{s v p}\right) p k \cdot K_{j, t}+\left(\tau_{j}^{t v a}+\tau_{j}^{a c c}+\tau_{j}^{s v b}\right) g o o d h d_{j, t} p p_{j, t}+\right. \\
& \left(\tau_{j}^{d d d}\left(1+\tau_{j}^{t v a}+\tau_{j}^{a c c}+\tau_{j}^{s v b}\right)+\tau_{j}^{t v a}+\tau_{j}^{a c c}+\tau_{j}^{s v b}\right) g o o d h i_{j, t} t c_{t} p w_{j}+ \\
& w_{t} l_{t}\left(\tau_{j}^{c s s}+\tau_{j}^{i m p o}-\tau_{j}^{c s s} \tau_{j}^{i m p o}\right)+p k_{t} \cdot K S_{t}+T R E S_{t} \\
& \operatorname{SavS}_{t}=I S_{t}-\sum_{j}\left(\operatorname{dgd}_{j} p p_{j, t}\left(1+\tau_{j}^{m c s}\right)+d g i_{j} t c_{t} \cdot p w_{j}\left(1+\tau_{j}^{m c s}\right)\right)-T R S_{t}-T_{R S E}
\end{aligned}
$$

\section{Rest of the world}

$$
\begin{aligned}
& x_{j, t}=\operatorname{xin}_{j}\left(\frac{p p_{j, t}}{t c_{t} \cdot p w_{j}}\right)^{\sigma x} \\
& \text { import }_{j}=\sum_{i} \sum_{j} \operatorname{cimp}_{i, j, t} I 14_{i, j}+i m p h_{j, t}+i n v i m p_{j, t}+d g i_{j} \\
& 0=\sum_{j} t c_{t} \cdot p w_{j} \cdot \text { import }_{j, t}-p p_{j, t}\left(1+\tau_{j}^{m c s}\right) x_{j, t}+w_{t} \cdot \operatorname{lm}-\left(w_{t} \cdot l x+T R X E_{t}\right)
\end{aligned}
$$

\section{Equilibrium}

$$
\begin{aligned}
& \sum_{j} l_{j, t}+l r_{t}+l i v_{t}+l x=l h_{t}+l m \\
& \sum_{j} K_{j, t}+K r_{t}+K i v_{t}+Y i v_{t}=K H_{t}+K S+K E \\
& p k_{t}\left(\sum_{j} K_{j, t}+K r_{t}+K i v_{t}\right)+\pi m o n_{t}\left(1-\tau^{s d}\right) Y i v_{t}=p k_{t}\left(K H_{t}+K S+K E\right) \\
& \operatorname{SavS}_{t}=I S_{t}-\sum_{j} d g d_{j} p p_{j, t}\left(1+\tau_{j}^{m c s}\right)+d g i_{j} t c_{t} p w\left(1+\tau_{j}^{m c s}\right)-T R S_{t}-T R S E-S V D_{t}-\tau^{s r} A t_{t-1} /\left(1+g_{T}\right) p r d_{t}
\end{aligned}
$$$$
\operatorname{SavE}_{t}=\sum_{j} \tau_{j}^{m c s}\left[\left(o_{j, t}-\operatorname{civdom}_{j, t}\right) p p_{j, t}+\left(\operatorname{import}_{j, t}-\operatorname{civimp}_{j, t}\right) \cdot t c_{t} \cdot p w+\tau_{j}^{d d d} i m p h_{j, t} t c_{t} \cdot p w\right.
$$$$
\left.+\left(\tau_{j}^{\mathrm{tva}}+\tau_{j}^{a c c}+\tau_{j}^{s v b}\right) \sum_{h}\left(d o m h_{h, j} p p_{j, t}+i m p h_{h, j, t} t c_{t} \cdot p w\left(1+\tau_{j}^{d d d}\right)\right)\right]
$$$$
+p k_{t} \cdot K E+T R H E+T R S E+T R X E-T R E H-T R E S
$$

walras $_{t}=\operatorname{pinv}_{t} \operatorname{InvS}_{t}+\operatorname{piv}_{t} Y_{i v}+\operatorname{prd}_{t} A_{t-1} /\left(1+g_{T}\right)-\left(\operatorname{SavS}_{t}+\operatorname{SavH}_{t}+\operatorname{SavE}_{t}\right)$

\section{Parameters and exogenous variables}

A1, A2, A3, A4, A5, A6, A7, A8, A9 - scale parameters in CES function $\alpha$ di, $\alpha e n, \alpha l, \alpha k, \alpha e, \alpha k l e, \alpha m, \alpha m i, \alpha r, \alpha i v, \alpha h, \alpha c i d, \alpha c i v, \alpha d v, \alpha v k, \alpha v l, \alpha v e, \alpha v m, \beta$ - share parameters

$\sigma, \sigma d i, \sigma e, \sigma k e, \sigma k l e, \sigma i v d i, \sigma c, \sigma x$ - elasticity rates

$\beta e n_{j}\left(\beta\right.$ nen $\left._{j}\right)$ - energy (non energy) input vector in sector $j$

$\beta e_{i}\left(\beta n e_{i}\right)$ - vector of energy (non energy) goods of type $i$

coef-CO2 emission coefficient

$\delta$ - capital depreciation rate

$\gamma$ - scale parameter

$I 14_{i, j}$ - unit matrix

props - saving propensity of households

$\rho$ - time preference rate

$\tau_{j}^{a c c}$ - excise rate

$\tau^{c s s}$ - social cotisation rate 
$\tau_{j}^{c s e}$ - payroll tax rate

$\tau_{j}^{\text {ddd }}$ - custom duty rate

$\tau_{j}^{i m p r}$ - tax rate on production

$\tau^{\text {impo }}$ - tax rate on individual income

$\tau_{j}^{m c s}\left(\tau_{i}^{m c s i}\right)$ - services and commercial margins in production (consumption)

$\tau_{t}^{\text {sd }}$ - subsidy rate for the development sector

$\tau^{s r}$ - subsidy rate for research

$\tau_{j}^{s v p}\left(\tau_{j}^{s v b}\right)$ - subsidy rate for production (consumption)

$\tau^{\text {svm }}$ - subsidiy rate for households

$\tau_{j}^{\text {tva }}$ - VAT rate

$\theta$ - intertemporal substitution elasticity

$K E, K S$ - firms and state capital

Im (lx) - supply (demand) labor from the rest of the world

lorm - labor norm

$p w$ - world price

TREH - transfers from firms to households

TRHE - transfers from households to firms

TRES - transfers from firms to state

TRXE - transfers from the rest of the wolrd to firms

xin $_{j}$ - reference exports

\section{Households}

$C$ - aggregated consumption

cidomh $_{j}$ - good consumption from sector $\mathrm{j}$

goodhd (goodhi) - domestic (imported) good consumption

SavH, SavE, SavS - saving of households, firms and state

lh - labor supply

pcgood - consumption price for the good $j$

pcgoodd-consumption price for the domestic good $j$

pcgoodi-consumption price for the imported good $j$

$p c$ - aggregated consumption price

TRS - social transfers

$K H, K S, K E$ - dividends received by households, state and firms

\section{Final good sector}

bivht $_{j}$ - demand for development investment goods

cidom $_{i, j}\left(\operatorname{cimp}_{i, j}\right)$ - domestic (imported) input demand

$\operatorname{cin}_{i, j}$ - input demand

$E_{j}$ - energy demand

$K_{j}$ - capital demand

$K L E_{j}$ - aggregated capital-labor-energy demand

$L_{j}$ - labor demand

$M_{j}$ - non-energy demand

$O_{j}$ - output 
$r k_{j}$ - gros capital price

$p c i_{i, j}$ - input price

$p e_{j}$ - energy input price

$\mathrm{pl}_{j}$ - gros labor cost

$\mathrm{pm}_{j}$ - non-energy input price

$p p_{j}$ - production cost

$\operatorname{ppin}_{i}$ - input price

$w$ - wage

Research sector

At - knowledge stock

$g$ - growth rate

$g_{T}$ - growth rate at the final period

$K r$ - capital demand

Lr - labor demand

prd - patent price

Development sector

civ ${ }_{j}$ - input demand

civdom $_{j}\left(\right.$ civimp $\left._{j}\right)$ - domestic (imported) input demand

Eiv - aggregated energy demand

Kiv - capital demand

Liv - labor demand

Miv - aggregated non-energy demand

Yiv- output

$\operatorname{pciv}_{j}$ - input price

peiv - price of the aggregated energy demand

pmiv - price of the aggregated non energy demand

pmon - monopoly price

piv - production price

zun - unitary profit

SVD - subsidies

\section{Investment}

invdom $_{j}\left(\right.$ invimp $\left._{j}\right)$ - domestic (imported) investment good supply

InvtS - aggregated standard investment supply

pinv - standard investment price

pinvdi $_{j}$ - price of the investment good $j$

$p k$ - capital price

$r$ - interest rate

\section{State}

dgd (dgi) - domestic (imported) consumption

IS - income

$V A T, D D D, A C C$ - value added taxes, customs and excise duties

$\operatorname{dif} C$ - adjustment variable for the state budget neutrality

Rest of the world

import $_{j}$ - imports in the sector $j$ 
tc - exchange rate

$x_{j}$ - exports

Appendix 3. Simulations results $(\%$, reference $=0)$

\begin{tabular}{|c|c|c|c|c|}
\hline \multirow[b]{2}{*}{ Variable } & \multicolumn{2}{|c|}{ Permit market } & \multicolumn{2}{|c|}{ CO2 Tax } \\
\hline & $\begin{array}{c}\text { Exogenous } \\
\text { dynamics }\end{array}$ & $\begin{array}{c}\text { Endogenous } \\
\text { dynamics }\end{array}$ & $\begin{array}{c}\text { Exogenous } \\
\text { dynamics }\end{array}$ & $\begin{array}{c}\text { Endogenous } \\
\text { dynamics }\end{array}$ \\
\hline Real GDP & 0.08 & 0.06 & -0.06 & -0.01 \\
\hline Aggregated output & 0.34 & 0.32 & -0.88 & -0.84 \\
\hline Permit price/ Taxe (€/tCO2) & 5.77 & 5.77 & 3.80 & 3.81 \\
\hline Industrial CO2 emissions & -15.16 & -15.16 & -15.83 & -15.82 \\
\hline ETS sectors' emissions & $-20,7$ & $-20,7$ & $-20,7$ & $-20,7$ \\
\hline Total CO2 emissions & -14.41 & -14.42 & -15.18 & -15.17 \\
\hline Energy inputs & 2.06 & 2.06 & -5.87 & -5.85 \\
\hline Total energy demand & 2.30 & 2.29 & -4.86 & -4.84 \\
\hline Energy intensity & 2.13 & 2.15 & -5.87 & -5.88 \\
\hline Energy dependency & -4.45 & -4.43 & 0.35 & 0.32 \\
\hline Growth Rate & - & 0.15 & - & -0.33 \\
\hline Saving (total) & 0.25 & 0.29 & 0.02 & -0.07 \\
\hline Households saving & -0.53 & -0.51 & -0.75 & -0.81 \\
\hline Enterprises saving & 0.03 & 0.00 & 0.35 & 0.41 \\
\hline Public deficit & 12.56 & 12.85 & 12.24 & 11.74 \\
\hline Total investment (volume) & 0.42 & 0.46 & 0.17 & 0.09 \\
\hline Standard investment & 0.42 & 0.46 & 0.17 & 0.09 \\
\hline Research output & - & -0.04 & - & -0.05 \\
\hline Development goods & - & 0.01 & - & -1.28 \\
\hline Standard capital price & -0.16 & -0.16 & -0.15 & -0.15 \\
\hline Patent price & - & 0.12 & - & -0.40 \\
\hline Development investment price & - & 0.09 & - & 0.79 \\
\hline Development investment cost & - & 0.09 & - & 0.79 \\
\hline Interest rate & 0.00 & 0.03 & 0.00 & -0.06 \\
\hline Imports & 0.06 & 0.06 & 0.13 & 0.13 \\
\hline Exports & -0.27 & -0.29 & -1.03 & -1.00 \\
\hline Exchange rate & -0.31 & -0.32 & -0.75 & -0.73 \\
\hline Equivalent Variation & 0.06 & -0.13 & 0.05 & 0.28 \\
\hline Households consumption & 0.17 & 0.13 & 0.49 & 0.58 \\
\hline Consumer price index & -0.13 & -0.13 & -0.05 & -0.06 \\
\hline Total income & 0.03 & 0.00 & 0.35 & 0.41 \\
\hline Wage income & 0.01 & 0.02 & -0.06 & -0.07 \\
\hline Capital income & 0.98 & 0.87 & 0.39 & 0.62 \\
\hline Monopoly profits & - & 0.11 & - & -0.50 \\
\hline Social transfers & -1.81 & -1.92 & 2.92 & 3.11 \\
\hline Employment & 0.01 & 0.02 & -0.06 & -0.07 \\
\hline
\end{tabular}

